SILVIA ELENA CAMPUSANO CUEVAS

Avaliação das lesões de golpe e contragolpe e padrão de lesão axonal difusa nos casos de trauma cranioencefálico em cães e gatos

São Paulo 


\section{Avaliação das lesões de golpe e contragolpe e padrão de lesão axonal difusa nos casos de trauma cranioencefálico em cães e gatos}

Dissertação apresentada ao Programa de PósGraduação em Patologia Experimental e Comparada da Faculdade de Medicina Veterinária e Zootecnia da Universidade de São Paulo para obtenção do título de Mestre em Ciências.

\section{Departamento:}

Patologia

Área de concentração:

Patologia Experimental e Comparada

\section{Orientador:}

Prof. Dr. Paulo César Maiorka

\section{Co-orientador:}

Dra. Adriana de Siqueira

São Paulo 
Autorizo a reprodução parcial ou total desta obra, para fins acadêmicos, desde que citada a fonte.

DADOS INTERNACIONAIS DE CATALOGAÇÃO NA PUBLICAÇÃO

(Biblioteca Virginie Buff D’Ápice da Faculdade de Medicina Veterinária e Zootecnia da Universidade de São Paulo)

T. 3480

FMVZ

Cuevas, Silvia Elena Campusano

Avaliação das lesões de golpe e contragolpe e padrão de lesão axonal difusa nos casos de trauma cranioencefálico em cães e gatos / Silvia Elena Campusano Cuevas. -2017.

$58 \mathrm{f}$ : : il.

Dissertação (Mestrado) - Universidade de São Paulo. Faculdade de Medicina Veterinária e Zootecnia. Departamento de Patologia, São Paulo, 2017.

Programa de Pós-Graduação: Patologia Experimental e Comparada.

Área de concentração: Patologia Experimental e Comparada.

Orientador: Prof. Dr. Paulo César Maiorka.

Co-orientador: Dra. Adriana de Siqueira.

1. Traumatismo craniano. 2. Beta-amiloide. 3. Patologia veterinária forense. 4. Maustratos. I. Título. 


\section{CERTIFICADO}

Certificamos que a proposta intitulada "Determinação das lesões de golpe e contra-golpe e padrão de lesão axonal difusa em animais que morreram por trauma cranioencefálico", protocolada sob o CEUA n 7749130215 , sob a responsabilidade de Paulo César Maiorka - que envolve a produção, manutenção e/ou utilização de animais pertencentes ao filo Chordata, subfilo Vertebrata (exceto o homem), para fins de pesquisa científica ou ensino está de acordo com os preceitos da Lei 11.794 de 8 de outubro de 2008, com o Decreto 6.899 de 15 de julho de 2009, bem como com as normas editadas pelo Conselho Nacional de Controle da Experimentação Animal (CONCEA), e foi aprovada, quanto ao mérito em 29/04/2015, e pelo envio dos números dos prontuários dos animais utilizados em 24/2/2017, pela Comissão de Ética no Uso de Animais da Faculdade de Medicina Veterinária e Zootecnia da Universidade de São Paulo (CEUA/FMVZ).

We certify that the proposal "Determination of the coup and counter-coup lesion and pattern of axonal diffuse lesion in animals that died due to traumatic brain injury", utilizing 10 dogs (10 males), protocol number CEUA7749130215, under the responsibility of Paulo César Maiorka - which involves the production, maintenance and/or use of animals belonging to the phylum Chordata, subphylum Vertebrata (except human beings), for scientific research purposes or teaching - is in accordance with Law 11.794 of October 8, 2008, Decree 6899 of July 15, 2009, as well as with the rules issued by the National Council for Control of Animal Experimentation (CONCEA), and was approved on merits on 04/29/2015, and by sending the numbers of the records of the animals used on 02/24/2017, by the Ethic Committee on Animal Use of the School of Veterinary Medicine and Animal Science (University of São Paulo) (CEUA/FMVZ).

Finalidade da Proposta: Mestrado

Vigência da Proposta: de 3/2015 a 3/2017 Área: Patologia Animal

Origem: HOVET/FMVZ/USP

Espécie: Cães Sexo: Machos Idade: ausente N: 10

Linhagem: N/A Peso: ausente

Resumo: O traumatismo cranioencefálico (TCE) é uma importante causa de morte e sequelas graves, tanto em humanos como animais. Apesar disso, ainda há poucos estudos sobre TCE em medicina veterinária. Assim, este estudo pretende descrever as principais alterações anatomopatológicas encontradas em animais que vieram a óbito por TCE, bem como determinar as lesões de golpe e contra-golpe e padrão de lesão axonal difusa, assim como outras alterações comumente encontradas, como hemorragias e edema. Ainda, pretende-se correlacionar as lesões encontradas com objetos e forças necessárias capazes de produzir tais lesões. Para tanto, serão realizados exames necroscópicos destes animais, devidamente identificados, e fotodocumentação. Será padronizada a coleta do encéfalo, realizando seis cortes tranversais no mesmo, que possibilitarão a análise das mesmas estruturas. O primeiro corte será do lobo frontal abrangendo o córtex cerebral; o segundo corte, mais caudalmente, abrangerá além do córtex, o joelho do corpo caloso; o terceiro corte será feito na região dos lobos parietal e temporal e abrangerá, além de córtex e corpo do corpo caloso, o III ventrículo e tálamo; o quarto corte será na região do lobo occipital e abrangerá o córtex, o esplênio do corpo caloso e o mesencéfalo; o quinto corte, abrangerá o cerebelo e a ponte do troco encefálico; e por último, o sexto corte será realizado na região de medula espinhal. O material será então processado histologicamente segundo as técnicas de rotina para confecção das lâminas, que serão coradas pela técnica de Hemtoxilina-Eosina (HE).

São Paulo, 24 de fevereiro de 2017.

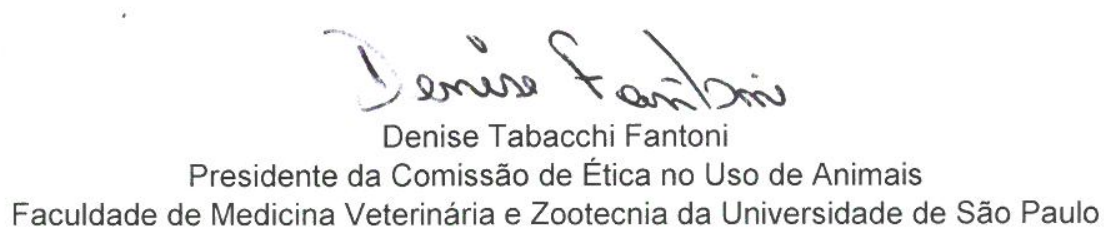

Av. Prof. Dr. Orlando Marques de Paiva, $n^{\circ} 87$

Fone: + 5511 3091-7676/0904 Cidade Universitária "Armando de Salles Oliveira"

Fax: $+55113032-2224$

São Paulo/SP - Brasil

e-mail: ceuavet@usp.br

$05508-270$

http://www.fmvz.usp.br/comissao-de-etica-www

http://orion.fmvz.usp.br/index.php\# 
FOLHA DE AVALIAÇÃO

Autor: CUEVAS, Silvia Elena Campusano

Título: Avaliação das lesões de golpe e contragolpe e padrão de lesão axonal difusa nos casos de trauma cranioencefálico em cães e gatos.

Dissertação apresentada ao Programa de Pós-Graduação em Patologia Experimental e Comparada da Faculdade de Medicina Veterinária e Zootecnia da Universidade de São Paulo para obtenção do título de Mestre em Ciências.

Data:

\section{Banca Examinadora}

Prof. Dr.

Instituição: Julgamento:

Prof. Dr.

Instituição: Julgamento:

Prof. Dr. Instituição: Julgamento: 
Á minha mãe Ruth, meus irmãos Felipe e Gabriel e minha cachorra Brigite,dedico. 


\section{AGRADECIMENTOS}

Ao professor e orientador Paulo César Maiorka pela confiança, orientação e paciência.

A Adriana por toda orientação, conversas e ajuda nas horas difíceis.

Aos membros da banca pela disponibilidade e contribuições.

A todos os professores do VPT, especialmente ao Prof. Catão e prof. Bruno pela disponibilização de equipamento fotográfico.

Ao pessoal do laboratório e a Prof. Claudia Mori, por todos os momentos compartilhados.

A todos os funcionários do VPT, Biblioteca e CEUA.

Aos amigos do departamento Raquel, Leo, Rafa, Dennis, Danilo, Mari, Thais, César e Pedro por todas as conversas, companheirismo, diversão e ajuda nas horas mais críticas.

Aos meus amigos C\&A que sempre esteve presente compartilhando as dificuldades e alegrias deste trajeto, à Jura por sempre estar ao meu lado, me escutando e ajudando sempre que possível, à Hang por sempre estar disposta a ajudar e por todas as conversas intermináveis sobre todos os assuntos possíveis, a todo o time de futsal por todas os momentos juntos. E aos demais amigos Kaki, Larva, Korri, Bentô por toda força e companheirismo. Agradeço a todos por todo o carinho.

À CAPES pela concessão da bolsa de estudos de mestrado. 


\section{RESUMO}

CUEVAS, S. E. C. Avaliação das lesões de golpe e contragolpe e padrão de lesão axonal difusa nos casos de trauma cranioencefálico em cães e gatos [Evaluation of coup and countercoup and pattern of diffuse axonal injury in cases of traumatic brain injury in dogs and cats]. 2017. 58 f. Dissertação (Mestrado em Ciências) - Faculdade de Medicina Veterinária e Zootecnia, Universidade de São Paulo, São Paulo, 2017.

O presente trabalho contempla o estudo das principais alterações macroscópicas e anatomopatológicas do sistema nervoso central (SNC) encontradas em animais que morreram em decorrência de traumatismo cranioencefálico (TCE). Além da determinação das lesões de golpe, contragolpe e padrão de lesão axonal difusa encontradas nesse tipo de trauma. Inicialmente realizou-se a necropsia dos animais com devido registro fotográfico, descrição das lesões macroscópicas e coleta de material para processamento histológico de rotina e confecção das lâminas coradas em hematoxilina-eosina (HE) para avaliação histopatológica. A imunohistoquímica foi realizada a partir dos mesmos segmentos utilizados nas lâminas de HE, com os anticorpos anti-proteína precursora do $\beta$-amiloide ( $\beta A P P)$, para determinação da lesão axonal, e anti-GFAP e anti-vimentina para avaliação de respostas do tecido nervoso à injúria, como astrocitose e astrogliose. Macroscopicamente as principais lesões observadas caracterizaram-se por lesões focais decorrentes de traumatismo direto, com fraturas de ossos do crânio, laceração de neuroparênquima e contusões. No exame histopatológico as lesões principais caracterizaram-se por hemorragia subdural e em neuroparênquima, congestão, edema tecidual e necrose em variados graus de intensidade e regiões do encéfalo. A lesão axonal foi confirmada pela imunomarcação do ßAPP que revelou marcação multifocal de axônios tumefeitos formando esferoides axonais, bulbos axonais ou axônios varicosos em alguns casos. Astrocitose, astrogliose e neovascularização foram observados na maioria dos casos através dos anticorpos GFAP e vimentina. Conclui-se no presente estudo que cães e gatos com TCE apresentaram lesões histologicamente caracterizadas por hemorragias multifocais em meninge e neuroparênquima em diversas regiões, além de edema, necrose e congestão, principalmente. A lesão axonal caracterizou-se pela formação de esferoides axonais, bulbos axonais e longos axônios varicosos. Esta característica foi observada em apenas 2 animais deste estudo, e destes apenas um 
animal (caso 6) apresentou um padrão de lesão axonal traumática difusa, confirmada pela presença de acentuada marcação pelo anticorpo ßAPP. Adicionalmente, foi observada astrocitose e astrogliose em cinco animais, principalmente das áreas próximas às lesões, avaliadas pelos anticorpos GFAP e vimentina.

Palavra-chave: Traumatismo craniano. Beta- amiloide. Patologia veterinária forense. Maus-tratos. Neuropatologia. 


\begin{abstract}
CUEVAS, S. E. C. Evaluation of coup and countercoup and pattern of diffuse axonal injury in cases of traumatic brain injury in dogs and cats [Avaliação das lesões de golpe e contragolpe e padrão de lesão axonal difusa nos casos de trauma cranioencefálico em cães e gatos]. 2017. 58 f. Dissertação (Mestrado em Ciências) Faculdade de Medicina Veterinária e Zootecnia, Universidade de São Paulo, São Paulo, 2017.
\end{abstract}

The present work contemplates the study of the main macroscopic and anatomopathological changes of the central nervous system (CNS) in animals that died due to traumatic brain injury (TBI). Besides the determination of the coup and countercoup and pattern of diffuse axonal injury in this type of trauma. Initially, the animals were necropsied and photographic recorded and macroscopic lesions were described and collect material for histological processing routine and the preparation of slides in hematoxylin-eosin (HE) staining for histopathological evaluation. Immunohistochemistry was performed from the same segments used in the HE slides, with anti- $\beta$-amyloid precursor protein antibodies ( $\beta A P P)$ for determination of axonal lesion, and anti-GFAP and anti-vimentin for evaluation of tissue responses to injury, such as astrocytosis and astrogliosis. Macroscopically, the main lesions observed were focal lesions due to direct trauma, such as skull fractures, neuroparenchyma laceration and contusions. In the histopathological evaluation, the main lesions were characterized by subdural hemorrhage and in neuroparenchyma, congestion, tissue edema and necrosis in varying degrees of intensity and regions of the encephalon. The axonal injury was confirmed by $\beta$ APP immunostaining that revealed multifocal labeled of swellings axons forming axonal spheroids, axonal bulbs or varicose axons in some cases. Astrocytosis, astrogliosis and neovascularization were observed in most cases through the antibodies GFAP and vimentin. In conclusion the present study demonstrate that dogs and cats with TBI presented histologically lesions characterized by multifocal hemorrhage in meninge and neuroparenchyma in different areas, as well as edema, necrosis and congestion, mainly. Axonal injury was determined by axonal swelling, bulbs and varicosities. This characteristic was observed in only 2 animals in this study, and only one of those (case 6) presented pattern of diffuse traumatic axonal injury, confirmed by accentuated $\beta$ APP labeling. Addiotionally, astrocytosis and astrogliosis was observed 
in five animals, mainly in areas close to lesions, evaluated by GFAP and vimentin antibodies.

Keywords: Traumatic brain injury. $\beta$-amyloid. Forensic veterinary pathology, Animal abuse. Neuropathology 
1 INTRODUÇÃO GERAL

Avaliação das Lesões de Golpe e Contragolpe e Padrão de lesão Axonal Difusa nos Casos de Trauma Cranioencefálico em Cães e Gatos

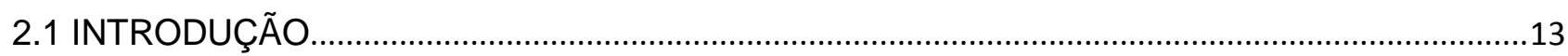

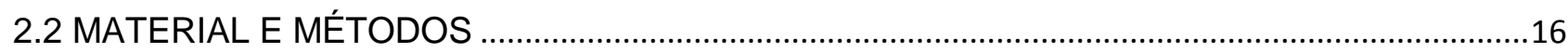

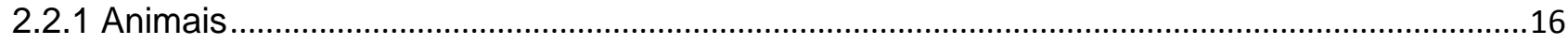

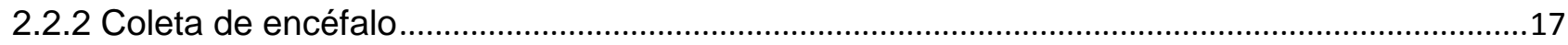

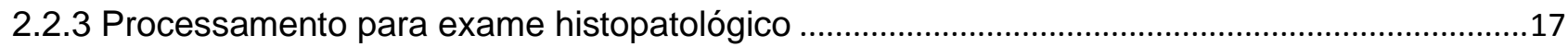

2.2.4 Imunohistoquímica (IHQ) - $\beta A P P$, GFAP e vimentina ............................................................18

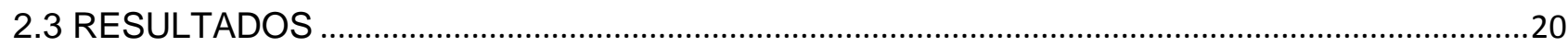

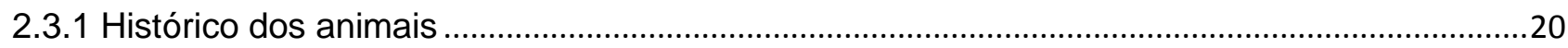

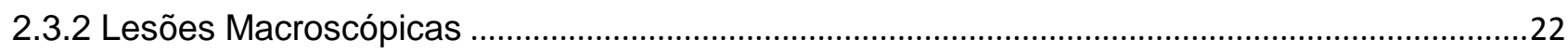

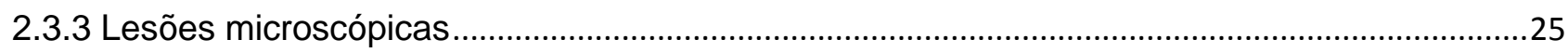

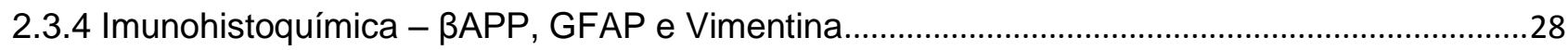

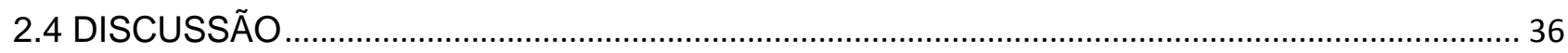

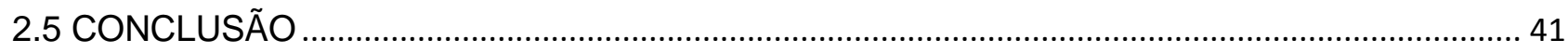

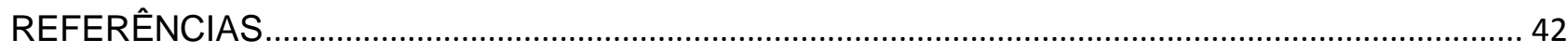

Lesão Axonal Difusa e Reação Astrocitária em Gato com Traumatismo Cranioencefálico .............. 50

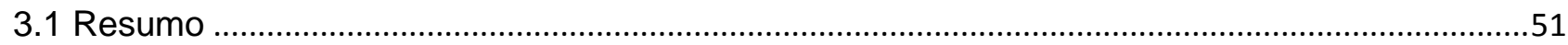

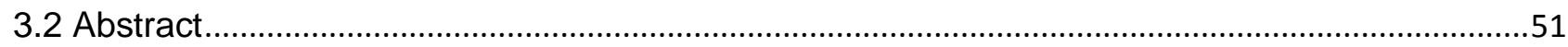

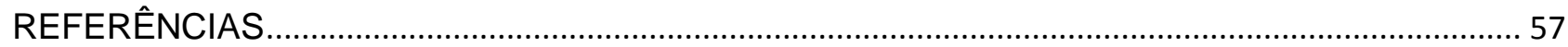




\section{INTRODUÇÃO GERAL}

O presente trabalho contempla o estudo das principais alterações macroscópicas e anatomopatológicas do sistema nervoso central (SNC) encontradas em animais que morreram em decorrência de traumatismo cranioencefálico. Além da determinação das lesões de golpe, contragolpe e padrão de lesão axonal difusa encontradas nesse tipo de trauma. Este trabalho será divido e apresentado em dois capítulos, de acordo com os artigos a serem publicados.

O capítulo 2 intitulado "Avaliação das lesões de golpe e contragolpe e padrão de lesão axonal difusa nos casos de trauma cranioencefálico em cães e gatos" teve como objetivo avaliar as principais lesões decorrentes de traumatismo cranioencefálico (TCE), através de análise histopatológica e imunohistoquímica. Foi realizada a necropsia dos animais com devido registro fotográfico e descrição das lesões macroscópicas, coleta de material e avaliação das alterações microscópicas através de processamento de rotina do material e coloração das laminas com hematoxilina-eosina. A imunohistoquímica foi realizada com os anticorpos antiproteína precursora do $\beta$-amiloide (ßAPP), para determinação da lesão axonal, antiGFAP e anti-vimentina para avaliação da resposta do tecido nervoso à injúria através da astrocitose e astrogliose.

O capítulo 3 intitulado " Lesão axonal difusa e reação astrocitária em gato com traumatismo cranioencefálico", apresentado na forma de um relato de caso (brief communication) de um dos casos retirado do capítulo 2, teve como objetivo destacar o padrão de lesão axonal difusa observado em um gato com TCE. O procedimento de descrição e avaliação das lesões macro e microscópicas se manteve igual ao realizado no capítulo 2, assim como a realização da reação imunohistoquímica com os anticorpos $\beta A P P$, GFAP e vimentina. 
Avaliação das Lesões de Golpe e Contragolpe e Padrão de lesão Axonal Difusa nos Casos de Trauma Cranioencefálico em Cães e Gatos 


\subsection{INTRODUÇÃO}

O traumatismo cranioencefálico (TCE) caracteriza-se por um dano físico ao tecido cerebral, acometendo as funções cerebrais normais de forma temporária ou permanente (PARIKH et al., 2007). A lesão encefálica definitiva que ocorre após o TCE é resultante de mecanismos fisiopatológicos que têm seu início no acidente e podem se estender por dias a semanas. Por esse motivo, as lesões cerebrais são classificadas em primárias e secundárias (GOODMAN, 1999). A lesão cerebral primária envolve ruptura física das estruturas do sistema nervoso, o que inclui danos diretos ao parênquima cerebral, e são classificadas como concussão, contusão, hematomas, laceração e lesão axonal difusa. Também pode ocorrer dano vascular direto, que leva a hemorragia intracraniana e edema vasogênico (DEWEY, 2000). A concussão é uma injúria cerebral leve caracterizada por perda transitória da consciência, sem alterações macro ou microscópicas do parênquima cerebral (SEIM, 2007; SANDE, 2012; LORENZ et al., 2011). A contusão é uma lesão moderada a grave que causa laceração do parênquima e/ou dos vasos sanguíneos, podendo haver hemorragia parenquimatosa ou edema (SEIM, 2007; SANDE, 2012; VERNEAU, 2005). Hematomas intra e extra axiais, nos espaços subaracnóide, subdural e epidural, podem causar compressão do cérebro e disfunção neurológica grave (DEWEY, 1993). A laceração é a lesão cerebral primária mais grave (SANDE, 2012; VERNEAU, 2005; DEWEY, 1993) e também pode haver hemorragia em parênquima cerebral ou edema, porém ocorre devido a fraturas de crânio e feridas penetrantes (SEIM, 2007; SANDE, 2012).

Os distúrbios e sinais clínicos variam de acordo com a gravidade de cada caso (SANDE, 2012). Por se tratar de um processo gerado por impacto, em que há deslocamento do cérebro no crânio, deve-se observar duas áreas importantes: a área de impacto chamada de golpe e a área contralateral ao golpe, chamada de contragolpe (SANDE, 2012; VERNEAU, 2005). É comum o desenvolvimento de sequelas, podendo ocorrer horas ou dias após o trauma, devido a liberação de mediadores inflamatórios (TNF- $\alpha$, IL-1 $\beta$ e IL-6), lesão axonal e hemorragia contínua (SANDE, 2012; VERNEAU, 2005; GEBHARD; LANG, 2008).

As lesões secundárias ocorrem de minutos a dias após o trauma e são causadas por uma combinação de insultos extracranianos sistêmicos e alterações físicas e bioquímicas intracranianas, que atuam em conjunto para perpetuar os 
danos do tecido cerebral. Elas são mediadas pelo aumento das atividades de neurotransmissores excitatórios, formação de espécies reativas de oxigênio e produção de citocinas pró-inflamatórias, como fator de necrose tumoral (TNF- $\alpha$ ), IL$1 \beta$ e IL-6, que podem contribuir com o dano neuronal e morte celular. Formação de edema cerebral, aumento da pressão intracraniana, comprometimento da barreira hemato-encefálica e alteração na reatividade vascular cerebral são as consequências das injúrias secundárias (HOPKINS, 1996; PROULX; DHUPA, 1998; FLETCHER; SYRING; 2009; CHESNUT, 1997).

As lesões no TCE podem ser classificadas em difusas e focais, e geralmente, há o predomínio de uma delas, porém ambas podem estar associadas em um único paciente. As lesões difusas acometem o cérebro com um todo e são decorrentes de forças cinéticas que causam rotação do encéfalo dentro da caixa craniana, podendo haver disfunções por estiramento ou ruptura de axônios e estruturas vasculares (MCCRORY; BERKOVIC, 2001; MCCRORY, 2001), e são comumente produzidas por acidentes automobilísticos e, em alguns casos, quedas e agressões (ADAMS et al., 1984; ADAMS et al., 1989; BLUMBERGS et al., 1989; GENNARELLI et al., 1982).

As lesões difusas são compostas pela concussão, a lesão axonal difusa e a tumefação cerebral. A lesão axonal difusa é definida na prática, como uma perda de consciência por mais de seis horas, associada ao TCE, sem lesão expansiva visível na tomografia que justifiquem o estado de coma do paciente (GENNARELLI; GRAHAM, 1998; SANJITH, 2011). Embora a lesão seja denominada como difusa, microscopicamente, a lesão axonal segue mais uma lesão de padrão multifocal na região subcortical e profunda da substância branca, mais na linha média, envolvendo estruturas como o corpo caloso, terceiro ventrículo e tronco encefálico (SANJITH, 2011). Há um comprometimento difuso do axônio e ocorrem hemorragias em locais distantes e isolados, o que indica que os vasos também foram estirados, ocasionando fragmentação e sangramento.

As lesões focais incluem os hematomas intra ou extracerebrais, as fraturas cranianas, que podem ser lineares ou associadas a afundamento focal, o hematoma extradural, o hematoma subdural agudo e a contusão cerebral. As fraturas cranianas lineares isoladas não causam danos cerebrais, porém elas podem estar associadas a lesão de estruturas vasculares, que podem causar complicações como o hematoma extradural (FRANCEL et al., 1996; ALDRICH et al., 1996). O hematoma 
extradural geralmente ocorre em casos de impacto craniano com baixa energia cinética, em que há ruptura de estruturas vasculares no espaço epidural, adjacente às linhas de fratura (BOR-SENG-SHU et al., 2004; BOR-SENG-SHU et al., 2006). O hematoma subdural agudo da mesma forma ocorre por energias cinéticas provenientes do acidente, também não sendo necessário neste caso, o contato do crânio com estruturas externas (TEASDALE; MATHEW, 1996). Neste caso, há rompimento das veias corticais durante o movimento de rotação, causando lesões secundárias associadas a liberação massiva de neurotransmissores excitatórios, devido a presença de sangue no espaço subdural em íntimo contato com o córtex. A contusão cerebral caracteriza-se por áreas hemorrágicas ao redor de pequenos vasos e tecido encefálico necrótico e podem ocorrer por ação direta ao parênquima, como em casos de fratura com afundamento craniano, ou pelo movimento do encéfalo, que pode ocasionar o esmagamento do parênquima contra a base do crânio ou outras estruturas rígidas. A contusão passará a ser chamada de laceração quando houver ruptura da pia-máter (SAWAUCHI et al., 2007).

A lesão axonal é um importante componente do TCE e ocorre devido o rompimento físico de axônios por forças em sentidos opostos (lesão axonal traumática) ou por isquemia (lesão axonal vascular) (BLUMBERGS et al., 2008)

A lesão axonal difusa caracteriza-se pela injúria generalizada aos axônios da substância branca, ocorrendo em diversos graus de lesão, desde uma concussão discreta a lesões fatais severas (BLUMBERGS et al., 1994; OEHMICHEN et al., 1998). Em medicina forense, a presença e distribuição de lesão axonal pode não só demonstrar a ocorrência de traumatismo cranioencefálico (GEDDES et al., 2000; REICHARD et al., 2005) como também pode ajudar a determinar o mecanismo de lesão em alguns casos (REICHARD et al., 2005; DOLINAK; REICHARD, 2006). A imunohistoquimica pelo anti- proteína precurso do $\beta$-amiloide pode demonstrar lesões em axônios em casos de animais sobreviverem pelo menos 2 horas ao trauma (GEDDES et al., 2000; REICHARD et al., 2005), enquanto que a detecção por outras técnicas histológicas requer uma sobrevivência de 15 a 24 horas (SHERRIFF et al., 1994; OEHMICHEN et al., 1998; BLUMBERGS et al., 2008). A proteína precursora do $\beta$-amiloide ( $\beta A P P)$ é um polipeptídeo sintetizado pela soma dos neurônios e transportado por transporte axonal rápido. A imunohistoquimica com o $\beta$ APP pode ser usada para determinar a distribuição e gravidade da lesão axonal, 
visto que essa lesão interrompe o transporte axonal, causa acúmulo de $\beta A P P$ em axônios inchados ou bulbos axonais (BLUMBERGS et al., 2008).

Apesar da alta ocorrência de TCE em animais, seja por acidentes como atropelamentos ou por maus-tratos, ainda há poucos estudos sobre as características das lesões e presença de lesão axonal difusa em animais. Estudos como este permitem um maior entendimento dos processos que ocorrem durante 0 TCE, podendo ajudar inclusive no procedimento clínico de animais com TCE. Portanto, este estudo tem como objetivo avaliar as lesões de golpe e contragolpe e do padrão de lesão axonal difusa em cães e gatos com TCE

\subsection{MATERIAL E MÉTODOS}

\subsubsection{Animais}

Foram utilizados sete animais, três das espécies canina e quatro da espécie felina, encaminhados ao Serviço de Patologia Animal do Departamento de Patologia da Faculdade de Medicina Veterinária e Zootecnia - USP (FMVZ-USP), com diagnóstico ou suspeita de traumatismo cranioencefálico sem outras alterações prévias em sistema nervoso central, para realização de exame necroscópico. Foram coletados os dados referentes ao animal como espécie, idade, sexo, raça, histórico, intervalo post mortem, conservação do cadáver e lesões macroscópicas foram obtidas a partir das requisições de necropsia, no período de 2013 a 2016.

Os animais com traumatismo cranioencefálico foram selecionados de acordo com informações obtidas pelo histórico do animal, fornecidas pelo proprietário ou pelo médico veterinário solicitante, de um evento traumático, somado à observação de sinais externos de TCE como contusões e abrasões na pele na região da cabeça (FINNIE, 2016). Para o grupo controle foram selecionados três animais sem histórico de sinais neurológicos, sem doenças infecciosas que acometem o SNC e sem sinais macroscópicos de TCE. 


\subsubsection{Coleta de encéfalo}

O exame necroscópico de cada animal foi devidamente foto documentado, utilizando-se uma régua graduada com a identificação do animal em cada fotografia. Todas as lesões e alterações macroscópicas foram registradas.

O encéfalo foi coletado integralmente e fixado em solução de formol tamponada a 10\%, na proporção volumétrica de $10: 1$, por cerca de 7 a 14 dias.

\subsubsection{Processamento para exame histopatológico}

Após a fixação, foram realizados de seis a sete cortes coronais de aproximadamente $2 \mathrm{~cm}$ (Figura 1) de espessura e foram realizados cortes menores armazenados em cassetes para posterior processamento do material para histologia e imuno-histoquímica. Durante esse processo, o encéfalo foi avaliado macroscopicamente e as lesões observadas foram descritas. Em seguida, os tecidos foram processados rotineiramente para histologia e mantidos em blocos de parafina. Foram realizados cortes de $5 \mu \mathrm{m}$ de espessura e corados com hematoxilina e eosina (HE) para avaliação histopatológica. Foram avaliadas diversas regiões do encéfalo, tais como córtex, tálamo, hipotálamo, hipocampo, corpo caloso, cápsula interna, tronco encefálico, cerebelo e medula cervical. 
Figura 1 - Cortes realizados no encéfalo após completa fixação

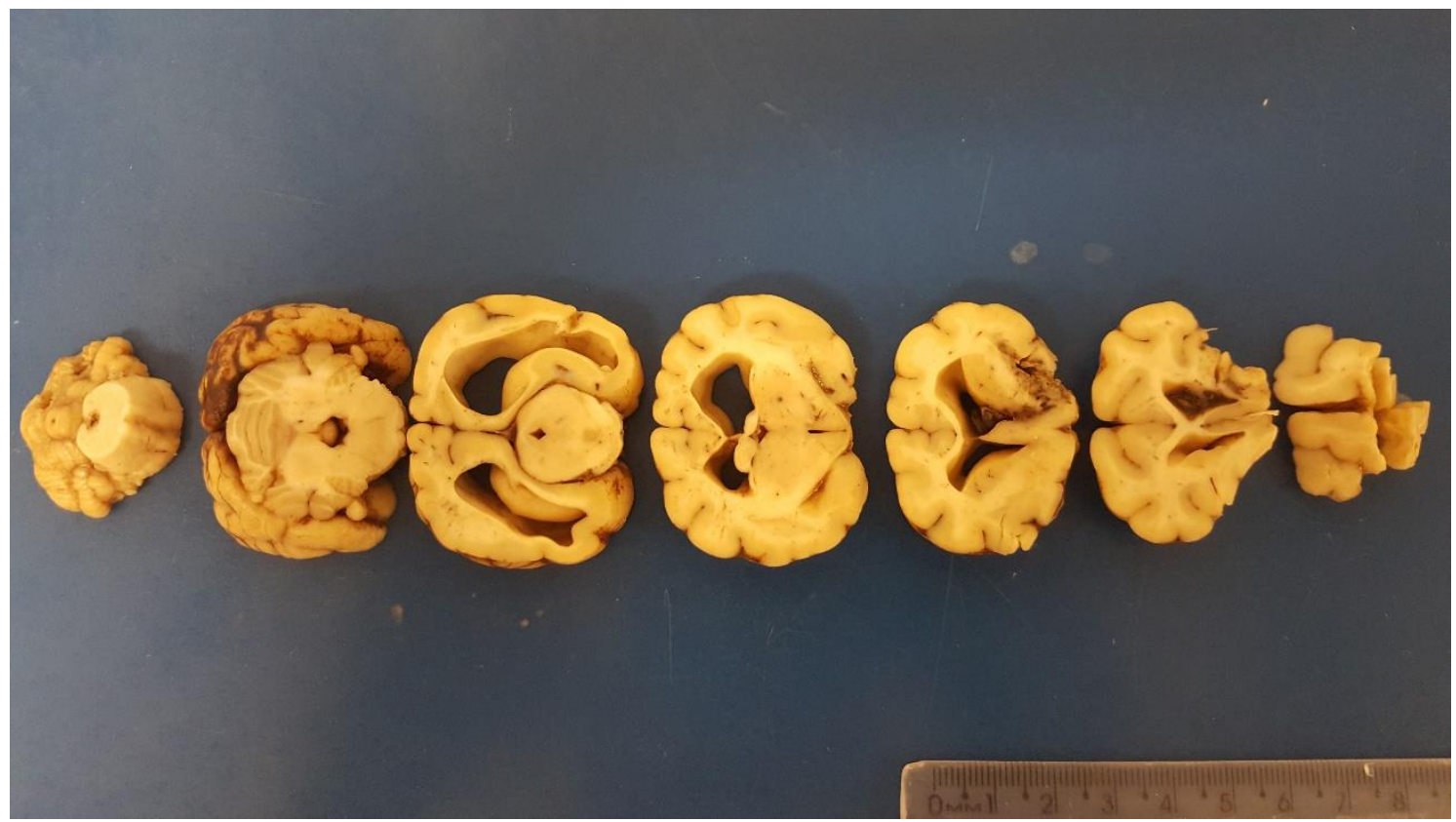

Fonte: (conteúdo próprio).

Legenda: Sete cortes sequenciais realizados transversalmente no sentido rostro-caudal do encéfalo de cada animal usado neste estudo

\subsubsection{Imunohistoquímica (IHQ) - $\beta$ APP, GFAP e vimentina}

A imuno-histoquímica foi realizada para os anticorpos das proteínas GFAP (Dako), Vimentina (Dako) e proteína precursora do $\beta$-amiloide (Millipore) em todas as regiões do SNC descritas anteriormente, utilizando-se o kit EnVision ${ }^{\mathrm{TM}}$ FLEX System da Dako. Os cortes foram submetidos a recuperação antigênica em tampão citrato de pH 6,0 em banho maria durante 25 minutos. Em seguida, os cortes foram incubados em uma solução de peróxido de hidrogênio durante 10 minutos, e depois, em uma solução $5 \%$ de leite em pó diluído em PBS, por mais 25 minutos. Foi realizada a incubação dos cortes nos anticorpos primários GFAP, vimentina e proteína precursora do $\beta$-amiloide overnight em geladeira, nas diluições 1:8000, 1:4000 e 1:200, respectivamente. Para os anticorpos vimentina e proteína precursora do $\beta$-amiloide, os cortes foram incubados por 30 minutos em um polímero (linker), em temperatura ambiente, para amplificar a reação, para em seguida ser realizada a incubação com o anticorpo secundário. Esta foi realizada para os três anticorpos, durante 30 minutos em temperatura ambiente. A revelação foi realizada utilizando-se o substrato DAB (3,3'-diaminobenzidina) permanecendo por 20 
minutos para GFAP e vimentina, e 30 minutos para a proteína precursora do $\beta$ amiloide, e a contra-coloração com hematoxilina.

Secções de encéfalo das mesmas regiões dos animais do grupo controle foram submetidas a reação imunohistoquímica com os mesmos anticorpos.

O anticorpo anti- ßAPP foi utilizado para determinação do padrão de lesão axonal, através da classificação de cinco padrões: lesão axonal traumática multifocal (mTAI - do inglês, multifocal Traumatic Axonal Injury), lesão axonal traumática difusa (dTAI - do inglês, diffuse Traumatic Axonal Injury), lesão axonal vascular (VAI - do inglês, Vascular Axonal Injury), lesão axonal metabólica (MAI - do inglês, Metabolic Axonal Injury) e lesão axonal penumbral (PAI - do inglês, Penumbral Axonal Injury). O dTAl é diagnosticado quando há histórico de trauma, com marcação dispersa ou em grupos de axônios com inchaço ou formando bulbos pelo BAPP, em corpo caloso, substância branca hemisférica, e tronco encefálico, em um padrão não consistente com lesão axonal vascular. O mTAl é diagnosticado quando há histórico de trauma com marcação dispersa ou em grupos de axônios com inchaço ou formando bulbos pelo $\beta A P P$, em corpo caloso, substância branca hemisférica, mas não no tronco encefálico, em um padrão não consistente com lesão axonal vascular. Os axônios imunorreativos da lesão axonal traumática difusa e multifocal estão normalmente dispersos ou em grupos ao longo do eixo longo do axônio. O VAl é um padrão de marcação axonal em "zigue-zague" devido comprometimento vascular, visto como áreas claramente demarcadas na substância branca devido predominantemente ao aumento da pressão intracraniana. O MAI ocorre quando há identificação de imunorreatividade de axônios dispersos sem um histórico clínico ou evidências patológicas de trauma e em um padrão não consistente com lesão axonal vascular, provavelmente devido a hipoglicemia ou, raramente, devido lesão hipóxicoisquêmica global. O PAI ocorre quando há marcação adjacente a lesões focais isoladas independente da etiologia, como infartos lacunares, lacerações corticais, abscessos, entre outros (REICHARD et al., 2003). A imunomarcação de cada região foi classificada em,,-+++ e +++, usando uma escala semi-quantitativa similar à descrita por Roe et al. (2014). Nesta classificação - caracteriza-se por marcação negativa; + trata-se de uma marcação discreta, na qual há baixo número de axônios positivamente marcados, geralmente necessitando uma objetiva de 40x para boa visualização; ++ significa uma marcação moderada, caracterizada por agrupamentos dispersos de axônios positivamente marcados ou número moderado de axônios 
individuais positivamente marcados; e +++ significa uma marcação acentuada, na qual há marcação extensa de grandes áreas da substância branca, visível com uma objetiva de $1,5 x$.

Os anticorpos anti-GFAP e anti-vimentina foram utilizados para avaliação da reação astrocitária, através dos aspectos morfológicos da célula, tais como tamanho e forma do corpo celular, tamanho do núcleo, distribuição da cromatina, número e comprimento dos prolongamentos das células. O padrão de imunorreatividade foi comparado entre os animais com TCE, que apresentaram diferentes intensidades de lesão do SNC (MESQUITA et al., 2016). A imunomarcação de cada região foi classificada em,,-+++ e +++, na qual + corresponde à marcação normal dos astrócitos pelo GFAP e das células endoteliais e ependimárias da vimentina, sem astrócitos reativos; + corresponde a uma discreta marcação de astrócitos pela vimentina e aumentada pelo GFAP; ++ corresponde a uma marcação moderada de astrócitos pela vimentina e moderadamente aumentada pelo GFAP; e +++, a uma marcação acentuada de astrócitos pela vimentina e acentuadamente aumentada pelo GFAP.

\subsection{RESULTADOS}

\subsubsection{Histórico dos animais}

O estudo foi composto por três cães e quatro gatos, de idades variadas, havendo cinco machos e duas fêmeas Informações como espécie, raça, sexo, idade e tipo de conservação de cadáver dos animais estão apresentadas na tabela 1. 
Tabela 1 - Informações dos animais com TCE.

\begin{tabular}{|c|c|c|c|c|c|c|}
\hline Caso & Espécie & Raça & Sexo & Idade & Conservação & $\begin{array}{c}\text { Intervalo post } \\
\text { mortem }\end{array}$ \\
\hline $\mathbf{1}$ & Canina & SRD & M & 6 anos & Não houve & 1 dia \\
\hline $\mathbf{2}$ & Felina & SRD & M & Filhote & Não houve & Desconhecido \\
\hline $\mathbf{3}$ & Felina & SRD & M & Filhote & Refrigeração & Algumas horas \\
\hline $\mathbf{4}$ & Canina & Pinscher & F & 9 meses & Refrigeração & Algumas horas \\
\hline $\mathbf{5}$ & Canina & Poodle & M & 13 anos & Refrigeração & Algumas horas \\
\hline $\mathbf{6}$ & Felina & SRD & F & 2 meses & Refrigeração & 1 dia \\
\hline $\mathbf{7}$ & Felina & SRD & M & 2 anos & Congelamento & 5 dias \\
\hline
\end{tabular}

O histórico dos animais revela que os animais 1, 2, 3 e 7 foram encontrados já mortos pelos proprietários e apenas um deles apresentou lesões claras de TCE, como laceração em pele em região frontal com exposição de tecido encefálico. Já os animais 4 e 5 apresentaram alterações clínicas com piora progressiva e posterior óbito, mas sem histórico evidente de trauma. Apenas o animal 6 apresentou histórico de trauma e sinais clínicos neurológicos com agravamento do quadro e morte após mais de 24 horas do trauma sem tratamento inicial. Os detalhes dos históricos de cada animal encontram-se na tabela 2. 
Tabela 2 - Histórico dos animais

\begin{tabular}{|c|c|}
\hline CASO & CIRCUNSTÂNCIAS DE ÓBITO \\
\hline 1 & $\begin{array}{l}\text { Canino encontrado morto pelo proprietário com um ferimento na cabeça e } \\
\text { presença de sangue ao redor do animal e em um pedaço de madeira encontrada } \\
\text { junto no local, proveniente de uma obra que estava sendo realizada no } \\
\text { condomínio vizinho. }\end{array}$ \\
\hline 2 & $\begin{array}{l}\text { Felino encontrado morto no acostamento de uma rua e por ser um animal de } \\
\text { descarte, não há mais dados sobre o mesmo. }\end{array}$ \\
\hline 3 & $\begin{array}{l}\text { Felino encontrado morto na rua (animal semidomiciliado), apresentando secreção } \\
\text { sanguinolenta nas vias nasal e oral e não apresentava sinais clínicos anteriores. }\end{array}$ \\
\hline 4 & $\begin{array}{l}\text { Proprietário relatou início de sinais clínicos neurológicos após realização de } \\
\text { cirurgia de ovariosalpingohisterectomia (OSH) com piora progressiva, } \\
\text { apresentando incoordenação motora mais acentuada em membros torácicos, } \\
\text { hiperextensão de membros e intensa vocalização, tendo sido realizada eutanásia } \\
\text { do cão. }\end{array}$ \\
\hline 5 & $\begin{array}{l}\text { Proprietário relatou que levou o cão ao pet shop pela manhã e que ao retornar } \\
\text { para casa o cão começou a apresentar hematêmese e prostração, indo a óbito no } \\
\text { início da tarde. }\end{array}$ \\
\hline 6 & $\begin{array}{l}\text { O felino foi encaminhado para necropsia dois dias após ter sido arremessado ao } \\
\text { chão. O animal foi levado a clínica veterinária, onde constatou-se midríase } \\
\text { bilateral, paralisia dos membros e inchaço na região frontal do crânio, mas não } \\
\text { sobreviveu. }\end{array}$ \\
\hline 7 & $\begin{array}{l}\text { O animal foi encontrado morto dentro do box do canil com cão e não há outras } \\
\text { informações a respeito. }\end{array}$ \\
\hline
\end{tabular}

\subsubsection{Lesões Macroscópicas}

Todos os animais apresentaram alterações macroscópicas em maior ou menor grau, condizentes com TCE. Os sete animais apresentaram hemorragias na região da cabeça, observadas externamente, após o rebatimento da pele ou observadas apenas após a retirada do encéfalo do crânio. Cinco animais (1, 3, 5, 6 e 7) apresentaram fratura de um ou mais ossos do crânio e dois animais apresentaram alterações em globo ocular. Apenas o animal 1 apresentou laceração em pele em região frontal, exposição e perda de massa encefálica (Figura 2), e destruição da arquitetura normal do órgão. A descrição das lesões encontra-se detalhada na tabela 3. 
Tabela 3 - Descrição das lesões macroscópicas dos animais com TCE.

\section{CASO LESÕES MACROSCÓPICAS}

Laceração em pele $(2,0 \mathrm{~cm})$ sobre região mediana do osso frontal, exposição do encéfalo e fragmentos de tecido encefálico aderidos aos pelos da região infraorbitrária esquerda. Hematomas e hemorragia em subcutâneo sobre o osso frontal, nasal, parietal e temporal, além de múltiplas fraturas com fragmentos livres, nos ossos frontal, parietal, interparietal, occipital (parte escamosa e basilar), etmoide, pré-esfenoide e basiesfenoide. Extensa laceração e focos hemorrágicos em hemisfério cerebral direito com perda da arquitetura externa normal, bem como congestão e edema.

2 Áreas de hemorragia subdural em região temporal direita

Múltiplas fraturas em osso nasal, maxilar, arco zigomático, frontal, zigomático, na região ventral do osso temporal e esfenóide. Encéfalo acentuadamente congesto,

3 com hemorragia em meninge principalmente sobre o hemisfério direito, além de hemorragia e coágulos aderidos em porção ventral do encéfalo, região de quiasma óptico

Encéfalo com discreto achatamento de giros e extensa área de hemorragia em ponte se estendendo à hipófise. Áreas lineares de hemorragia em porção basilar do osso occipital e em região de fossa hipofisaria, além de dilatação bilateral do ventrículo lateral com hemorragia

Fraturas em ossos frontal, parietal, temporal esquerdos, pterigoide e vômer,

5 associado a hemorragia. Encéfalo moderadamente congesto, principalmente no hemisfério direito.

Edema em região frontal do crânio, mucosa palpebral bilateral evidente, edemaciada e hiperêmica. Região subcutânea e crânio adjacente ao edema com acentuada hemorragia e coágulos aderidos, área focal de hemorragia em região de articulação atlanto-occipital e fratura em região orbital de osso temporal

6 direito. Acentuada hemorragia sub-meningeana em lobo temporal direito e acentuada hemorragia focal em medula na região atlanto-occipital. Encéfalo edemaciado, hiperêmico e com áreas hemorrágicas multifocais, moderada perda de tecido encefálico em região dorsal do lobo frontal. Assoalho cerebral com hiperemia e áreas hemorrágicas multifocais.

Moderada secreção sanguinolenta em narina direita, derrame hemorrágico em conjuntiva direita e área de hematoma em região temporal direita estendendo-se até o pavilhão auricular direito. Extensa hemorragia em região temporal bilateral e

7 fratura completa de osso parietal direito com afundamento ósseo e exposição de massa encefálica e hemorragia. Encéfalo encontrava-se avermelhado com fragmentos ósseos aderidos ao lobo temporal direito e fratura incompleta de osso pré-esfenoide direito em extensão a fratura do osso parietal direito. 
Figura 2 - Lesões macroscópicas do TCE em caso 1: cão, macho, SRD, 6 anos

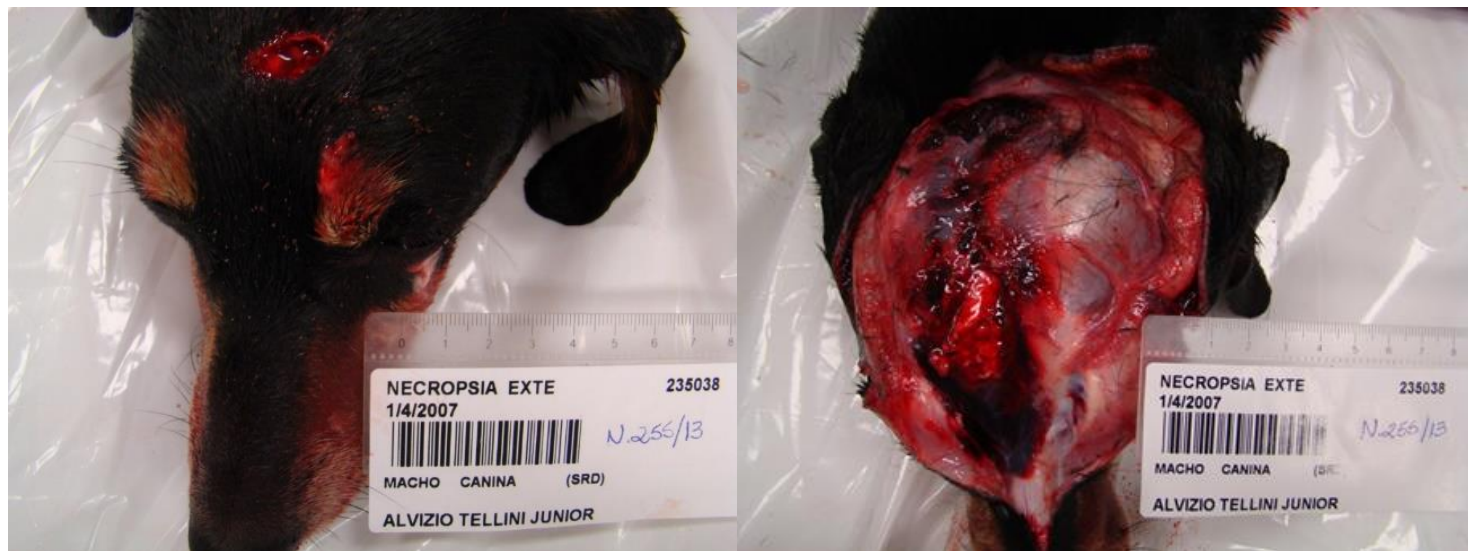

Fonte: (Departamento de Patologia Animal - FMVZ/USP)

Legenda: Caso 1. Cão com laceração em pele de aproximadamente $2,0 \mathrm{~cm}$ de extensão sobre a região mediana do osso frontal, com exposição de tecido encefálico (A). Mesma região da figura $A$, com a pele rebatida, revelando hematomas, hemorragias sobre os ossos frontal, nasal, parietal e temporal, com visualização de tecido encefálico (B).

Figura 3 - Fratura em crânio do animal 3 felino, SRD, macho, filhote

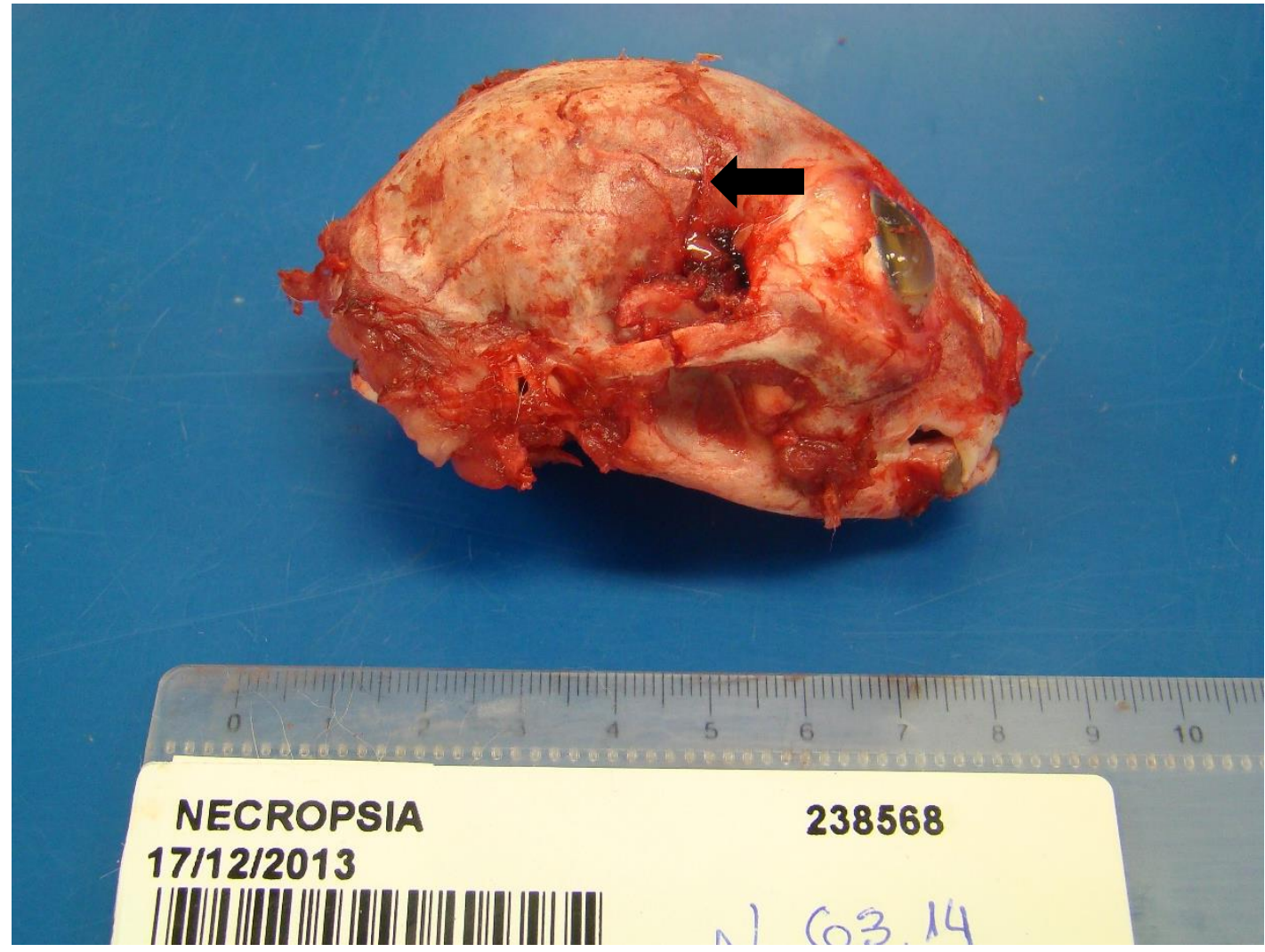

Fonte: (Departamento de Patologia Animal - FMVZ/USP)

Legenda: Fratura em osso temporal (seta) do caso 3 com pequena hemorragia adjacente à fratura. 


\subsubsection{Lesões microscópicas}

As lesões microscópicas foram descritas após avaliação dos cortes corados em HE em microscopia de luz. Todos os animais apresentaram focos hemorrágicos em meninge e neuroparênquima, necrose, edema (Figuras 4, 5, 6 e 7) e congestão. Também foi possível observar tumefação celular, esferoides axonais, gliose, neovascularização, neuronofagia, neurônios em cromatólise e discretas células inflamatórias. As lesões microscópicas e sua distribuição no SNC estão descritas na tabela 4.

Figura 4 - Lesões microscópicas do caso 1. Hematoxilina e eosina (HE)

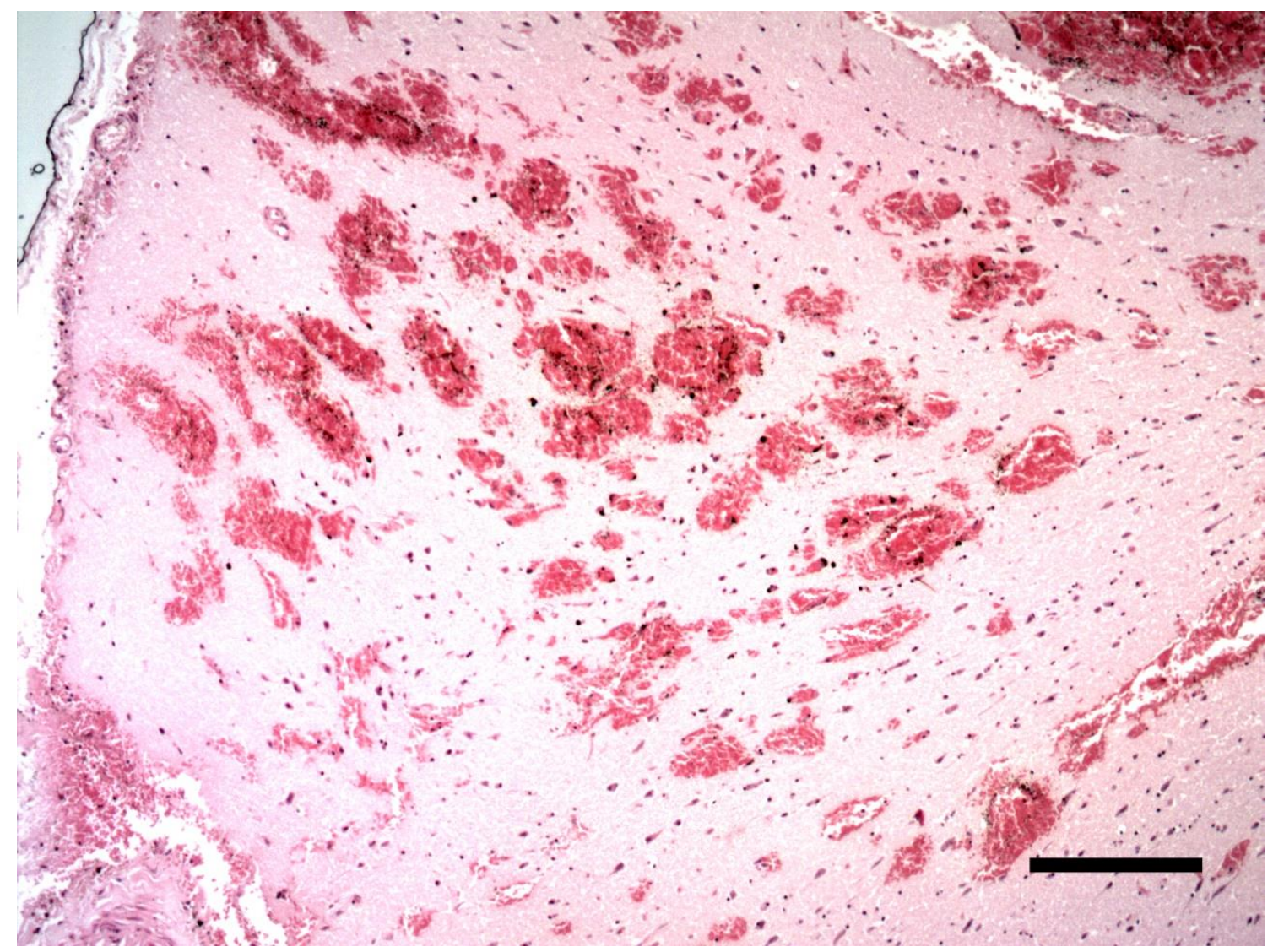

Fonte: (Cuevas, S.E.C).

Legenda: Extensa área de hemorragia multifocal em córtex telencefálico. Barra = $500 \mu \mathrm{m}$ 
Figura 5 - Foco hemorrágico em neuroparênquima do animal 6. Hematoxilina e eosina (HE)

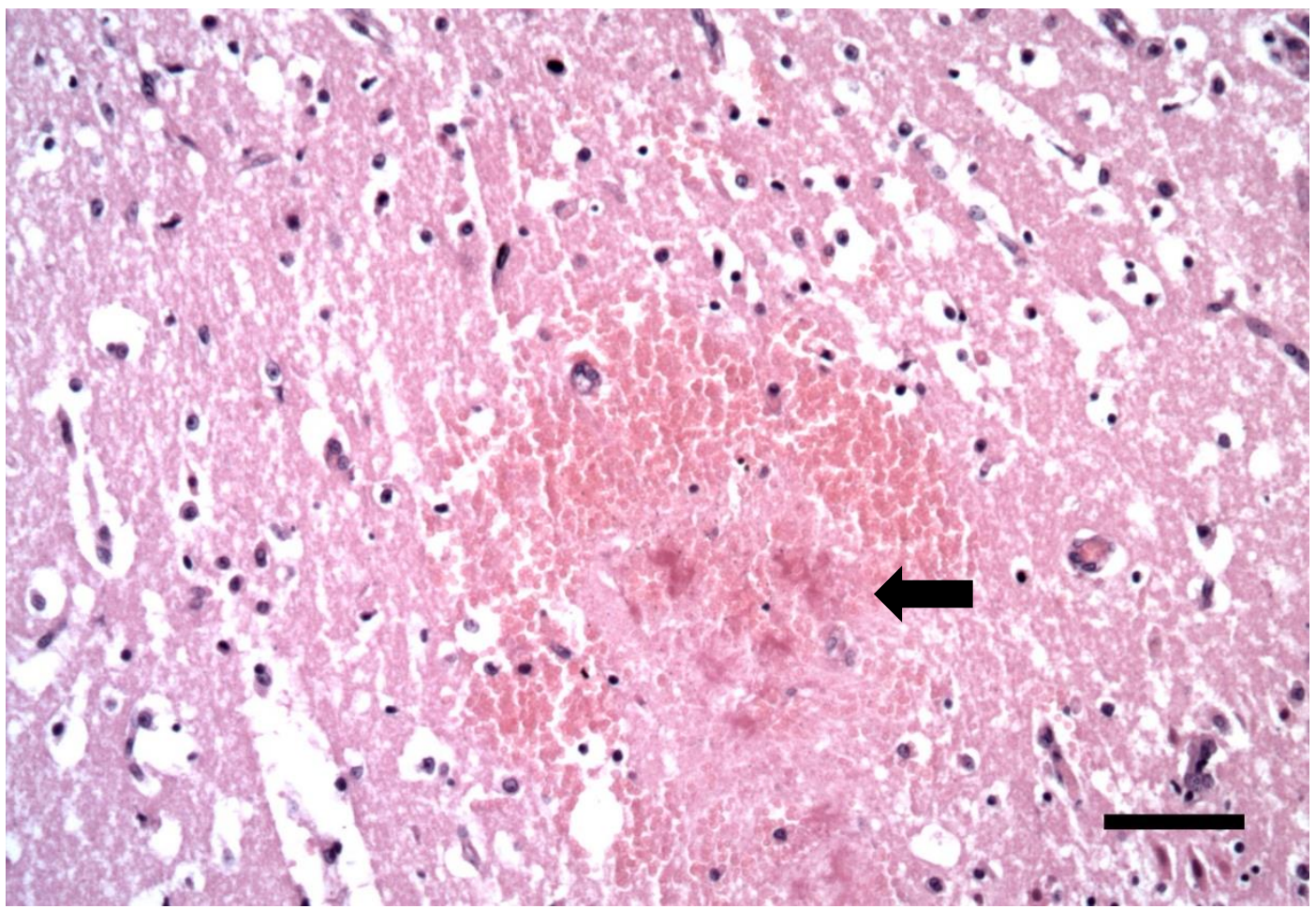

Fonte: (Cuevas, S.E.C)

Legenda: Foco hemorrágico em lobo piriforme com centro necrótico, caracterizado pelas áreas eosinofílicas (seta). Também é possível observar acentuado edema do neuroparênquima adjacente. Barra $=200 \mu \mathrm{m}$

Figura 6 - Extensa hemorragia em meninge de animal 6. Hematoxilina e eosina (HE)

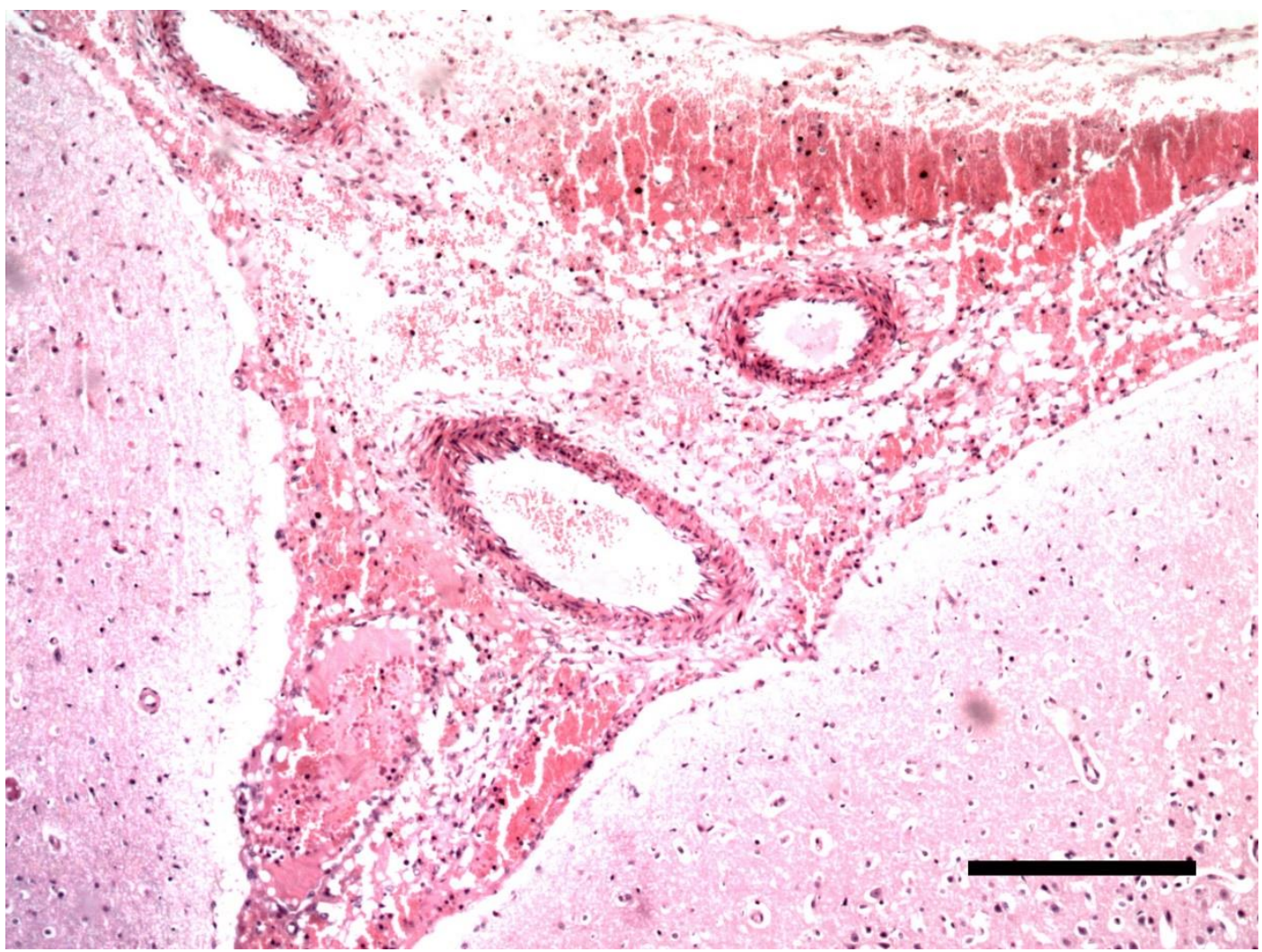


Fonte: (Cuevas, S.E.C).

Legenda: Extensa hemorragia em meninge. Barra $=500 \mu \mathrm{m}$

Figura 7 - Foco hemorrágico em tronco encefálico do animal 4. Hematoxilina e eosina (HE)

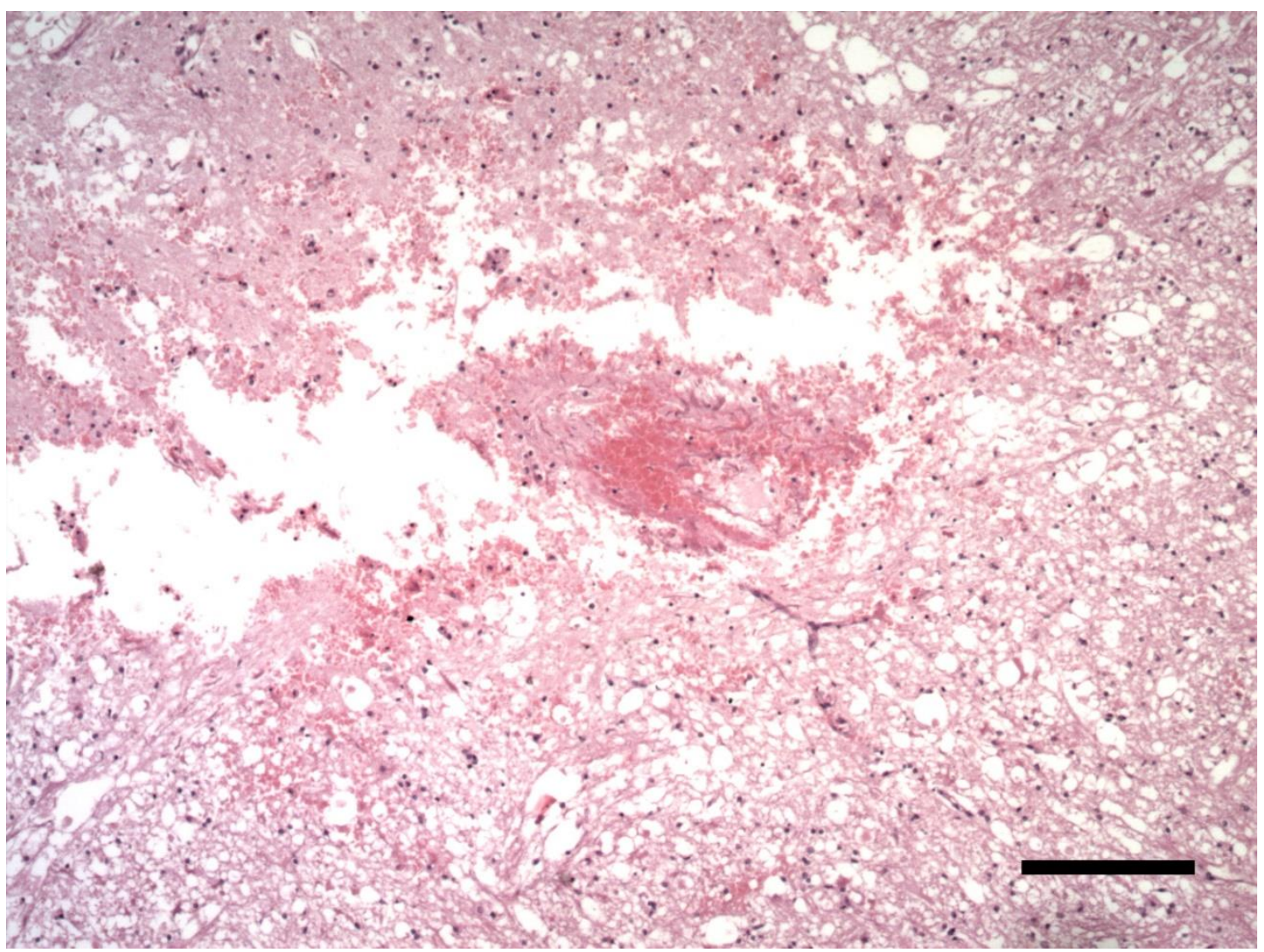

Fonte: (Cuevas, S.E.C).

Legenda: Extenso foco hemorrágico com necrose central e acentuado edema de neuroparênquima adjacente em bulbo. Barra $=500 \mu \mathrm{m}$ 
Tabela 4 - Descrição das lesões microscópicas dos animais com TCE

\section{CASO LESÕES MICROSCÓPICAS}

Extensa área de hemorragia em meninge e áreas hemorrágicas multifocais em córtex telencefálico; perda da arquitetura normal do órgão; hemorragia multifocal em

1 cerebelo, congestão acentuada e discreto a moderado edema; necrose neuronal discreta adjacente às áreas de hemorragia; discreta neuronofagia e presença de neurônios em cromatólise.

2 Hemorragia multifocal em meninge, córtex telencefálico, e tronco encefálico; grumos de pequenas estruturas basofílicas em meninge (bacilos da putrefação).

Extensa área de hemorragia em córtex telencefálico de lobo frontal direito, extensa hemorragia em meninge e focos hemorrágicos em parênquima adjacente (tálamo)

3 com discreta necrose neuronal; focos hemorrágicos em região septal, plexo coroide e tálamo, bem como moderado edema e congestão de vasos, gliose, neuronofagia e discreta cromatólise.

Extensa área de necrose e hemorragia em bulbo (Figura 7), necrose neuronal, edema moderado e discretos esferóides axonais em neuroparênquima adjacente. Extensas

4 áreas de hemorragia em plexo coróide, meninge e lobo piriforme, e hemorragia multifocal moderada em cerebelo. Necrose neuronal em córtex telencefálico e hipocampo, neuronofagia e gliose moderados.

Focos hemorrágicos em córtex telencefálico com necrose neuronal focal adjacente e

5 edema, e discreta hemorragia multifocal em cerebelo e ponte. Edema e gliose discretos, congestão acentuada e neurônios com cromatólise

Hemorragia multifocal em lobo piriforme e lobo frontal com discreta fibrina no centro da lesão. Acentuada reação vascular em áreas adjacentes à hemorragia, tumefação

6 axonal e fragmentação mielínica, necrose neuronal difusa acentuada, hemorragia subdural, presença de macrófagos ativados e fragmentos de fibrina em vasos sanguíneos com distribuição multifocal, bem como edema difuso acentuado, espongiose e necrose liquefativa

7 Sinais de autólise, extensas áreas de hemorragia em córtex telencefálico, meninge, plexo coroide, lobo piriforme e ventrículo lateral, além de edema, gliose.

\subsubsection{Imunohistoquímica - $\beta$ APP, GFAP e Vimentina}

Os mesmos cortes usados para a avaliação em HE, foram submetidos à imunohistoquímica com os anticorpos BAPP, GFAP e Vimentina e analisados em microscópio de luz.

A marcação pelo anticorpo ßAPP foi observada em apenas 2 dos 7 animais analisados, em diferentes graus. Destes, apenas um apresentou lesão axonal condizente com lesão axonal difusa (caso 6), no qual observou-se acentuada marcação multifocal de axônios em cápsula interna, adjacente à 
extensa área de hemorragia em lobo piriforme, e em tronco encefálico, bem como moderada marcação em substância branca de lobo temporal e discreta em corpo caloso. As marcações mais acentuadas ocorreram em áreas adjacentes à extensas áreas de hemorragia em meninge e neuroparênquima. No caso 4 o animal apresentou marcação moderada apenas em região de bulbo, ao redor da área de hemorragia e necrose, com poucos e esparsos bulbos axonais e axônios varicosos. A descrição do grau e localização das marcações dos casos encontram-se na tabela 5 .

Os axônios marcados apresentaram-se tumefeitos e observaram-se três formatos característicos: axônios inchados e redondos de tamanhos variados chamados de esferoides axonais; ovalados, denominados de bulbos axonais ou, se seccionados longitudinalmente, apresentam inchaço irregular ao longo do axônio, recebendo o nome de axônios varicosos (Figura 9).

Não houve nenhuma marcação em axônios nos animais do grupo controle.

Tabela 5 - Localização e intensidade da imunomarcação do anticorpo $\beta A P P$

\begin{tabular}{c|ccccc}
\hline \multicolumn{7}{c}{ Localização } \\
\hline Caso & $\begin{array}{c}\text { Subst. } \\
\text { Branca LT* }\end{array}$ & Corpo Caloso & $\begin{array}{c}\text { Cápsula } \\
\text { Interna }\end{array}$ & $\begin{array}{c}\text { Tronco } \\
\text { Encefálico }\end{array}$ & $\begin{array}{c}\text { Subst. Branca } \\
\text { Cerebelo }\end{array}$ \\
\hline 1 & - & - & - & - & - \\
\hline 2 & - & - & - & - & - \\
\hline 3 & - & - & - & - & - \\
4 & - & - & - & ++ & - \\
\hline 5 & - & - & - & - & - \\
\hline 6 & +++ & + & +++ & +++ & - \\
\hline 7 & - & - & - & - & - \\
\hline
\end{tabular}

LT: lobo temporal 
Figura 8 - Marcação de axonios pelo $\beta A P P$ em cápsula interna de animal 6 . IHQ

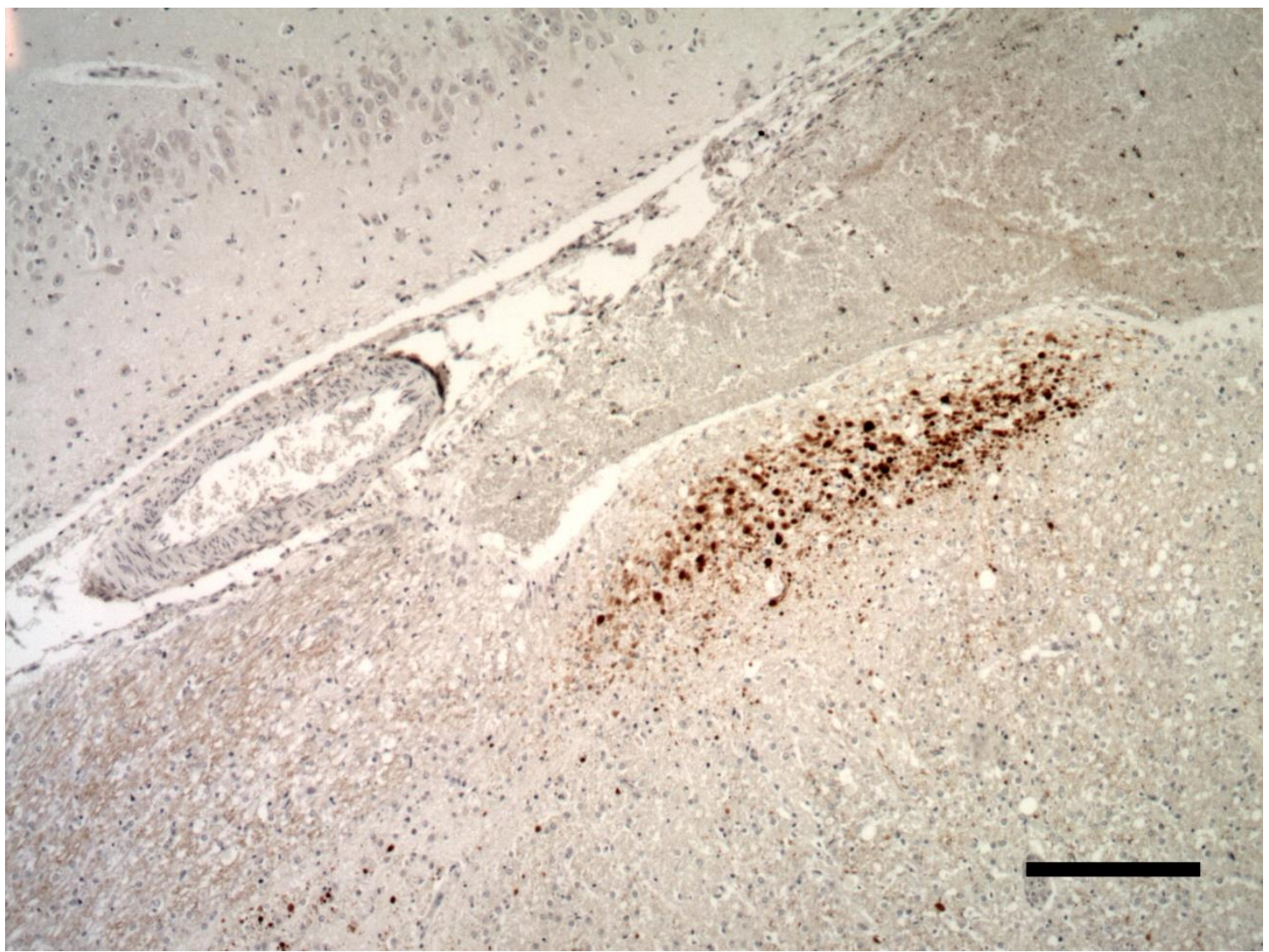

Fonte: (Cuevas, S.E.C).

Legenda: Foco de imunomarcação pelo $\beta A P P$ em cápsula interna adjacente à hemorragia subaracnóide. Barra $=500 \mu \mathrm{m}$ 
Figura 9 - Marcação axonal por ßAPP do animal 6 em substância branca de lobo temporal. $\mathrm{IHQ}$

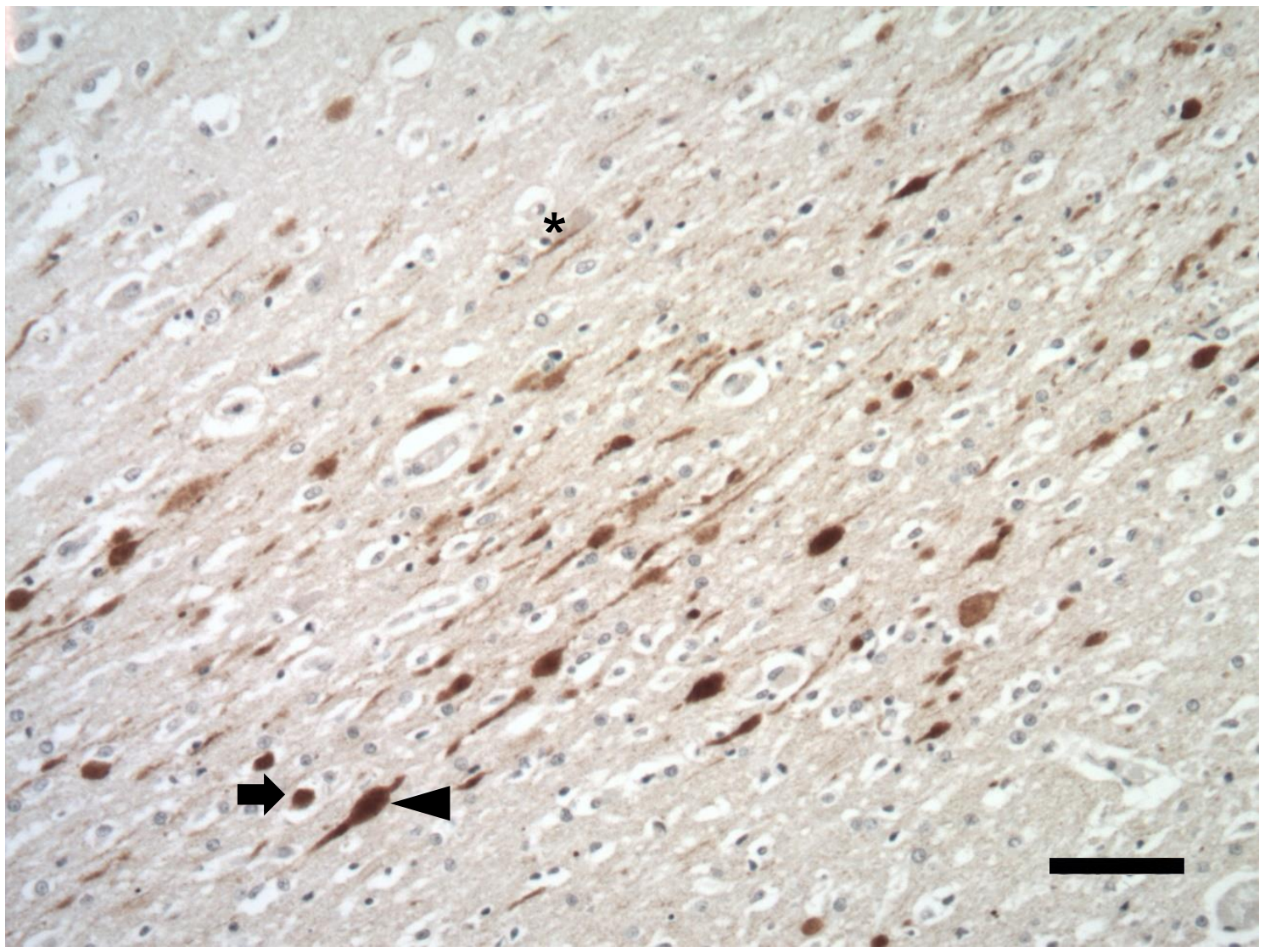

Fonte: (Cuevas, S.E.C).

Legenda: Axonios marcados pelo ßAPP em substância branca de lobo temporal. Observa-se os

três padrões de marcação axonal: esferoides axonais (seta), bulbos axonais (cabeça de seta) e axônios varicosos (asterisco). Barra $=200 \mu \mathrm{m}$

A reação astrocitária foi avaliada através da imunomarcação dos anticorpos GFAP e vimentina, cuja localização e intensidade de marcação para cada anticorpo estão apresentadas na tabela 6. Diversas áreas do SNC de cinco animais apresentaram astrócitos reativos, principalmente em tronco encefálico, córtex telencefálico e cerebelo, em áreas próximas às lesões. Dois animais apresentaram astrocitose acentuada em diversas regiões (casos $4 \mathrm{e}$ 6), enquanto nos casos 2 e 3 houve marcação discreta a moderada em apenas uma área analisada (tronco encefálico e córtex frontal direito, respectivamente). No caso 5 observou-se discreta marcação em corpo caloso, tronco encefálico e medula. A imunomarcação no córtex telencefálico ocorreu em lobo frontal direito do caso 3 e em lobo temporal direito no caso 6 . No cerebelo a imunomarcação pelo GFAP se deu tanto em substância branca como na 
camada granulosa, e pela vimentina se deu apenas em substância branca (caso 4), e apenas em substância branca no caso 5 de forma discreta por ambos anticorpos. Ainda no cerebelo, observou-se discreta marcação das células gliais de Bergmann em áreas próximas às lesões por ambos anticorpos (caso 4).

Através da reação imunohistoquímica foi possível observar que os astrócitos reativos apresentaram citoplasma abundante mais fortemente corado pelo anti-GFAP, prolongamentos em maior quantidade, mais longos e com diâmetro maior (astrogliose) que astrócitos de outras áreas do encéfalo ou pertencentes ao grupo controle. Os núcleos também se apresentaram maiores e com nucléolos evidenciados. A imunomarcação pela vimentina em astrócitos é semelhante à do GFAP, marcando intensamente seu citoplasma e prolongamentos quando há expressão dessa proteína em resposta à injúria. Foi possível observar essa marcação em 5 dos 7 animais. Deve-se destacar, que devido a vimentina marcar as células endoteliais em condições normais, foi possível avaliar a presença de neovascularização no SNC desses animais. Quatro animais (2, 3, 4 e 6) apresentaram moderada a acentuada neovascularização, sendo em três casos de forma difusa (casos 3,4 e 6), e no caso 2, que apresentou moderada neovascularização em córtex telencefálico. $\mathrm{Na}$ maior parte das áreas imunopositivas notou-se correspondência entre as marcações dos dois anticorpos, havendo diferença apenas entre a intensidade da marcação. A vimentina teve uma marcação mais forte que o GFAP em corpo caloso, cápsula interna e lobo piriforme, no entanto, em áreas como córtex telencefálico, tálamo, tronco encefálico e cerebelo o GFAP apresentou imunomarcação mais acentuada que a vimentina.

Os casos 1 e 7 apresentaram marcação semelhante à observada nos animais do grupo controle, com ausência de astrócitos reativos. 
Tabela 6 - Localização e intensidade da imunomarcação dos anticorpos GFAP e vimentina.

\begin{tabular}{|c|c|c|c|c|c|c|c|c|c|c|c|c|c|c|c|c|c|c|}
\hline \multicolumn{19}{|c|}{ Localização* } \\
\hline & \multicolumn{2}{|c|}{ CT } & \multicolumn{2}{|c|}{$\mathrm{CC}$} & \multicolumn{2}{|c|}{ Ta } & \multicolumn{2}{|c|}{$\mathrm{Cl}$} & \multicolumn{2}{|c|}{$\mathrm{Hi}$} & \multicolumn{2}{|c|}{ LB } & \multicolumn{2}{|c|}{$\mathrm{TE}$} & \multicolumn{2}{|c|}{$\mathrm{Ce}$} & \multicolumn{2}{|c|}{ Me } \\
\hline Caso & $\mathrm{V}^{* *}$ & $\mathrm{G}^{* *}$ & V & G & V & G & V & G & V & G & V & G & V & G & V & G & V & $\mathrm{G}$ \\
\hline 1 & - & - & - & - & - & - & - & - & - & - & - & - & - & - & - & - & - & - \\
\hline 2 & - & - & - & - & - & - & - & - & - & - & - & - & + & ++ & - & - & - & - \\
\hline 3 & + & ++ & - & - & - & - & - & - & - & - & - & - & - & - & - & - & - & - \\
\hline 4 & - & - & ++ & + & + & +++ & - & - & - & +++ & - & - & ++ & +++ & + & +++ & +++ & +++ \\
\hline 5 & - & - & + & - & - & - & - & - & - & - & - & - & - & - & + & + & + & - \\
\hline 6 & + & ++ & - & - & - & - & +++ & - & + & - & +++ & +++ & - & + & - & - & - & - \\
\hline 7 & - & - & - & - & - & - & - & - & - & - & - & - & - & - & - & - & - & - \\
\hline
\end{tabular}

*CT: Córtex Telencefálico; CC: Corpo Caloso; Ta: Tálamo; Cl: Cápsula Interna; Hi: Hipocampo; LB: Lobo Piriforme; TE: Tronco Encefálico; Ce: Cerebelo; Me: Medula.

** V: vimentina; G: GFAP

Figura 10 - Marcação pelo anticorpo GFAP em córtex de lobo piriforme do animal 6. IHQ

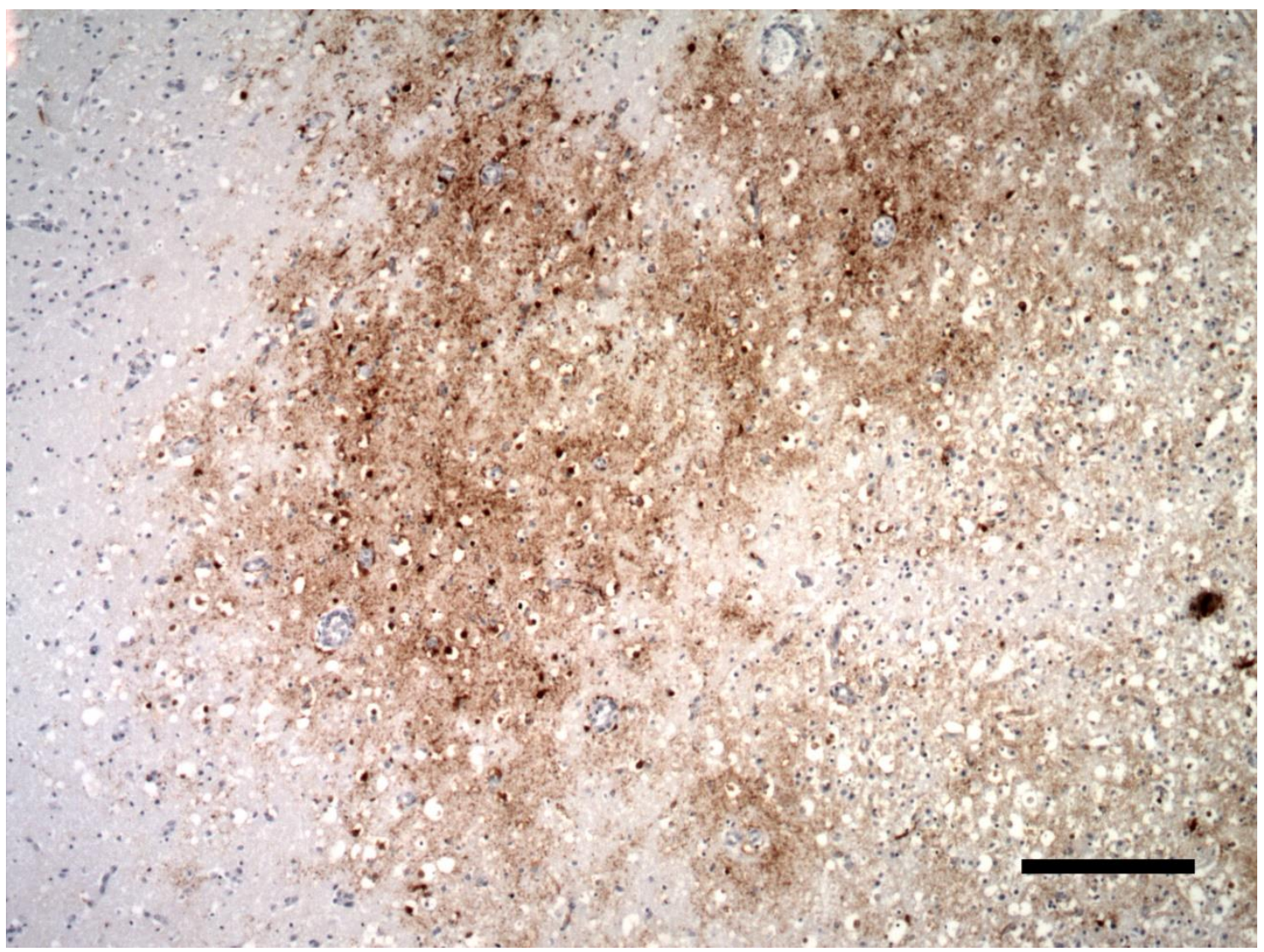

Fonte: (conteúdo próprio). 
Legenda: Astrocitose e astrogliose acentuda em lobo piriforme em área próxima à extensa hemorragia do caso 6 . Barra $=500 \mu \mathrm{m}$

Figura 11 - Marcação pelo anticorpo GFAP em córtex de lobo piriforme do animal 6. IHQ

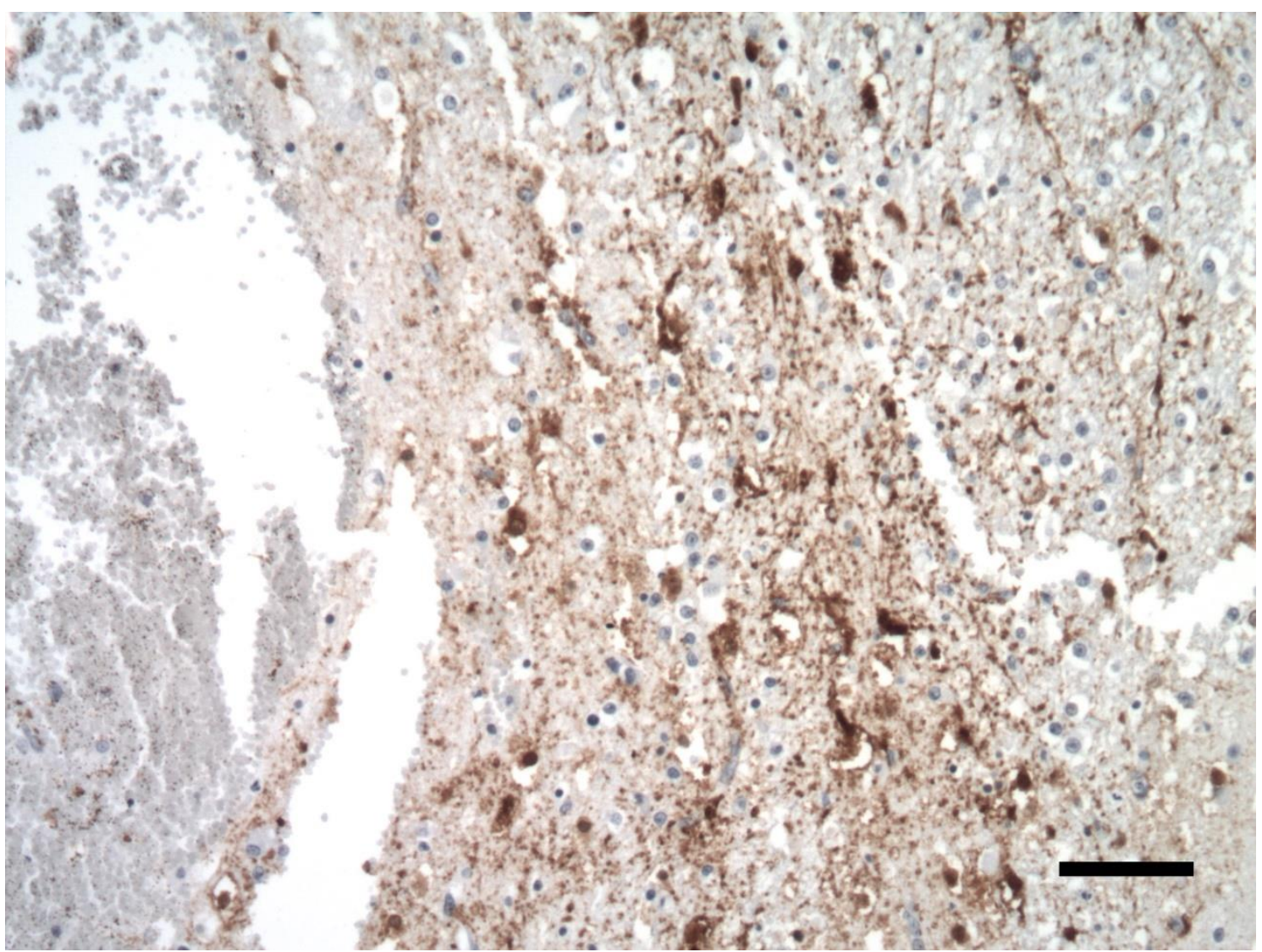

Fonte: (conteúdo próprio).

Legenda: Acentuada astrocitose e astrogliose em lobo piriforme do animal 6 evidenciada pela marcação do GFAP com área extensa de hemorragia à esquerda da imagem.

Destaque para o aumento em número e tamanho dos prolongamentos astrocitários.

Barra $=200 \mu \mathrm{m}$ 
Figura 12 - Marcação pelo anticorpo vimentina em tronco encefálico do caso 4. IHQ

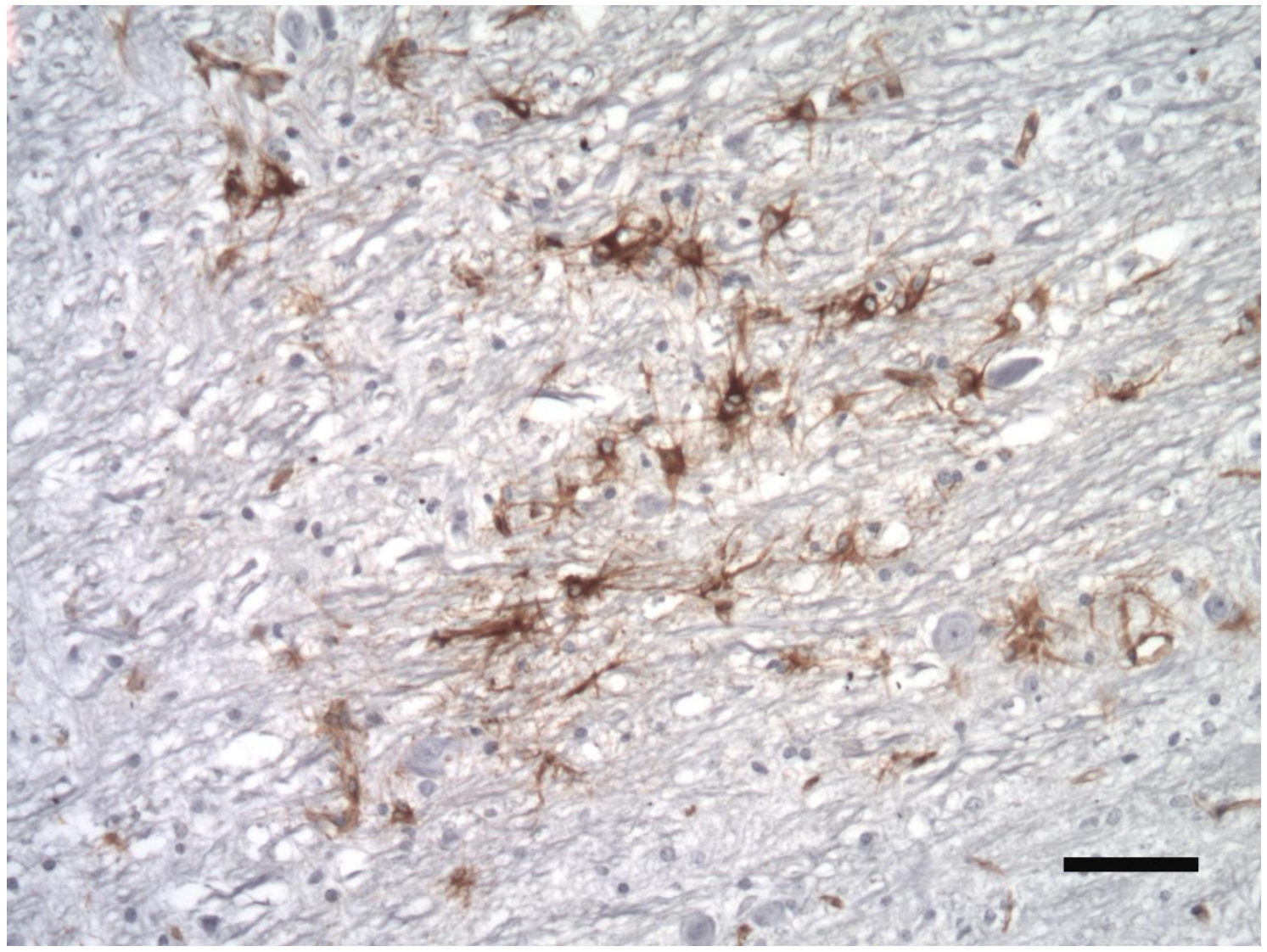

Fonte: (conteúdo próprio).

Legenda: Marcação de astrócitos pela vimentina em tronco encefálico do caso 4 próximo a extensa área de hemorragia e necrose. Destaque para os muitos prolongamentos de cada astrócito Barra $=200 \mu \mathrm{m}$ 
Figura 13 - Marcação pelo anticorpo vimentina em lobo temporal do caso 6. IHQ

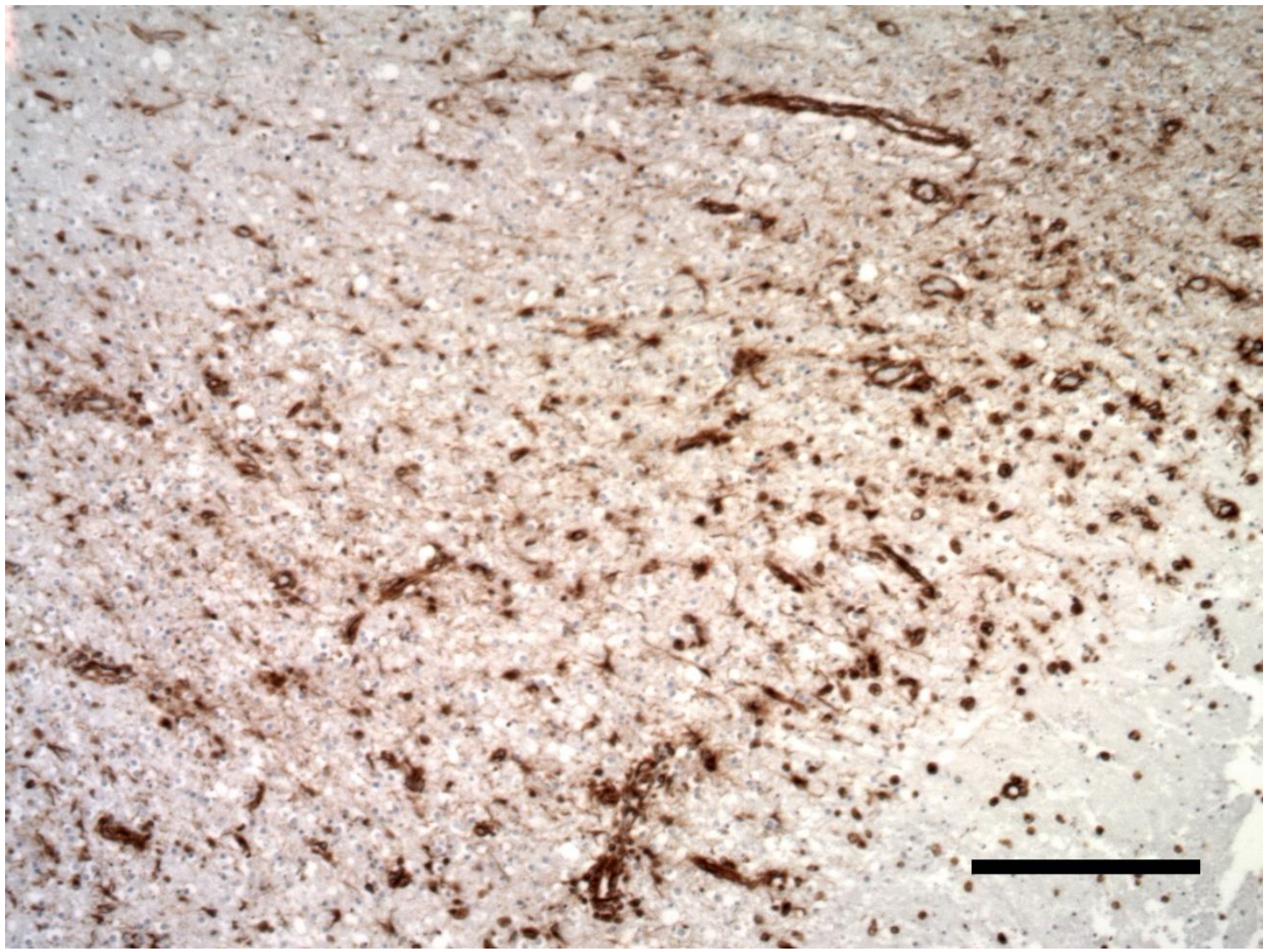

Fonte: (conteúdo próprio).

Legenda: Acentuada astrocitose e astrogliose em córtex de lobo temporal evidenciada pela imunomarcação da vimentina. Além da marcação dos astrócitos há intensa marcação

de pequenos vasos, caracterizando a formação de novos vasos como resposta tecidual. Barra $=200 \mu \mathrm{m}$

\subsection{DISCUSSÃO}

Todos os animais avaliados neste estudo apresentaram lesões macroscópicas condizentes com TCE (FINNIE, 2014; FINNIE, 2016) desde hemorragias em meninge observadas apenas na retirada do encéfalo do crânio, como nos casos 2 e 4, até lesões evidentes observadas já no exame externo do animal, como lacerações em pele na região da cabeça, fratura dos ossos cranianos com exposição de tecido encefálico (caso 1) e acentuado aumento de volume da região da cabeça (caso 6). Dois animais não tinham histórico de trauma prévio à sua morte, apresentando sinais clínicos variados e 
piora progressiva até o óbito (casos 4 e 5). Quatro animais foram encontrados mortos, sem sinais clínicos anteriores (casos 1, 2, 3 e 7) e apenas um animal tinha o histórico de traumatismo, apresentando sinais clínicos progredindo para o óbito (caso 6).

As lesões decorrentes de TCE ocorrem principalmente pelo contato direto com a cabeça ou por forças de aceleração/desaceleração. As lesões por trauma direto resultam em lesões focais, como lacerações do couro cabeludo, fraturas dos ossos do crânio (associada ou não à hematoma epidural) contusões e lacerações ocorrem quando a cabeça atinge ou é atingida por um objeto (ANDERSON; MCLEAN, 2005). As lesões causadas por forças de aceleração/desaceleração resultam mais frequentemente em dano difuso, como hemorragias subdural, subaracnoide, em neuroparênquima e lesão axonal difusa (OMMAYA et al., 2002). A maioria das lesões macroscópicas observadas são consistentes com lesões focais decorrentes do impacto direto na cabeça do animal e são semelhantes aos resultados obtidos nos estudos de TCE em focas (SPRAKER; LANDER, 2010) e em filhotes de leões marinhos (ROE et al., 2014).

O caso 1 apresentou apenas área de golpe, devido ao extenso trauma com destruição da arquitetura normal do hemisfério direito. No animal 2 verificou-se macroscopicamente apenas hemorragia subdural em região temporal direita, enquanto na microscopia observou-se além de foco hemorrágico em córtex telencefálico de lobo temporal, área hemorrágica em tronco encefálico, podendo ser a lesão de contragolpe, dependendo do ângulo do trauma na cabeça do animal. $O$ animal 3 apresentou lesões tanto macro quanto microscópicas, como hemorragia, em lobo frontal e temporal e em porção ventral do encéfalo, na região de quiasma óptico, tálamo e região septal, caracterizando assim a lesão de contragolpe. No caso 4 não foram observadas lesões condizentes com área de contragolpe, as lesões observadas microscopicamente correspondem apenas à área de hemorragia em ponte estendendo-se à hipófise, observada durante a coleta do encéfalo. No caso 5, macroscopicamente observou-se apenas foco hemorrágico em lobo frontal direito e microscopicamente, discreta hemorragia multifocal em ponte e cerebelo, caracterizando uma discreta área de contragolpe. $O$ animal 6 apresentou área de golpe em lobo temporal direito caracterizado por extensa 
hemorragia multifocal. A área de contragolpe foi observada em lobo temporal/ piriforme do hemisfério esquerdo, também caracterizada por hemorragia multifocal. $O$ animal 7 apresentou macroscopicamente hemorragia e aderência de fragmento ósseo em lobo temporal direito, caracterizando a área de golpe, enquanto microscopicamente observaram-se áreas de hemorragia em lobo piriforme, caracterizando-se como lesão de contragolpe.

Neste estudo apenas dois dos sete animais com TCE apresentaram imunomarcação pelo anticorpo $\beta$ APP (casos 4 e 6). Isto, pode ser explicado pelo o $\beta$-amiloide não ter sido encontrado em todos os axônios danificados, como mostra o estudo de Smith et al. (2003), apesar de estudos terem demonstrado que o $\beta$-amiloide se co-acumula com o APP em axonios tumefeitos ao longo do encéfalo com lesão (SMITH et al., 1999; IWATA et al., 2002; STONE et al., 2002, SMITH et al., 2003). A lesão axonal é uma das características mais importantes e comuns do TCE difuso em humanos (ADAMS et al., 1991; SMITH; MEANEY, 2000). O dano aos axônios pode prejudicar o transporte axonal levando ao acúmulo de proteínas, incluindo a proteína precursora de amiloide (APP) (GENTLEMAN et al., 1993; LEWEN et al., 1995; PIERCE et al., 1996; SHERRIFF et al., 1994; WILKINSON et al., 1999).

Houve marcação de axônios varicosos pelo $\beta$-amiloide nos casos 4 e 6 , o que difere de estudos que demonstraram que o $\beta$-amiloide foi encontrado tipicamente em bulbos axonais e não nos alongados axônios varicosos, que por sua vez marcaram com o anticorpo para APP. Assim, apenas o transporte axonal interrompido não parece explicar o acúmulo de $\beta$-amiloide, mas a desconexão do axônio pode favorecer processos que levam a produção e/ou acumulo do $\beta$-amiloide, como o aumento da proteólise da APP (SMITH et al., 2003). No entanto, isso pode ser possível nos casos em que não houve marcação pelo anticorpo, como no caso 5 deste estudo em que não houve imunomarcação apesar da sobrevivência de pelo menos algumas horas do animal. Porém, não se pode descartar a possibilidade de o $\beta$-amiloide ter se acumulado em regiões que não foram examinadas ou que a produção e acumulo de $\beta$-amiloide possa ser mais demorada em alguns pacientes (SMITH et al., 2003). 
Outra explicação para a não marcação é o tempo de sobrevivência dos animais, visto que a lesão axonal é progressiva (POVLISHOCK; CHRISTMAN, 1995) e, portanto, animais que morrem rapidamente após o trauma apresentarão escores de marcação mais baixos do que aqueles que sobrevivem por horas a dias (SMITH et al., 2003). O acumulo de APP em fibras danificadas próximas a área de lesão pode ser visível ao microscópio de luz em 1,75 a 3 horas após o trauma (BLUMBERGS et al., 2008) não havendo marcação se a morte do animal for muito rápida ou imediata ao trauma.

Enquanto o rompimento mecânico completo dos axônios (axotomia primária) pode ocorrer após lesão craniana severa, a lesão axonal evolui com mais frequência ao longo do tempo (axotomia secundária), levando a uma eventual desconexão. Na maioria dos casos a axotomia secundária demora muitas horas após o insulto inicial, resultando eventualmente em degeneração walleriana do segmento distal do axônio (CHRISTMAN et al., 1994; MAXWELL et al., 1993). Este fato pode ser mais um motivo pelo qual não houve imunomarcação pelo ßAPP na maioria dos casos deste estudo, no qual dos cinco casos, quatro (casos 1, 2, 3 e 7) foram encontrados já mortos sem sinais clínicos anteriores ao óbito. Apenas o caso 2 que o animal foi encontrado morto no acostamento de uma rua, com fortes indícios de atropelamento, não havendo informações sobre seu estado físico anterior ao óbito.

O caso 6 foi o único que apresentou marcada imunorreatividade pelo BAPP em diferentes áreas do SNC, enquadrando-se no padrão de lesão axonal traumática difusa. Características como o tempo de sobrevivência elevado do animal e conhecido histórico de trauma com presença de forças de aceleração/desaceleração condizem com todos os estudos sobre lesão axonal apresentados até o momento.

Neste estudo observou-se astrocitose e astrogliose em cinco dos sete animais analisados, em diferentes áreas do SNC e diferentes graus, principalmente próximo a áreas de lesões observadas em HE. Observou-se aumento do número de astrócitos em substância cinzenta, evidenciada pela marcação de GFAP em hipocampo e GFAP e vimentina em tálamo no caso 4, e áreas do córtex telencefálico e lobo piriforme no caso 6 , evidenciados tanto pelo GFAP quanto pela vimentina, próximo as áreas de lesão. Astrogliose ocorre quase que invariavelmente nestes casos com TCE, no qual os astrócitos 
reativos apresentam aumento da imunopositividade da proteína ácida fibrilar glial (GFAP) e um citoplasma eosinofílico frequentemente expandido devido à absorção da proteína plasmática extravasada (CLARK; KOCHANEK, 2001). Visto que os astrócitos são células que respondem prontamente a ampla variedade de insultos ao tecido nervoso (TAKAMIYA et al., 1988; MONTGOMERY, 1994; PEKNY et al., 1999; DONG; BENVENISTE, 2001) tais como isquemia, trauma, desmielinização, inflamação, neurodegeneração e infecções virais (PETITO et al., 1990; ENG; GHIRNIKAR, 1994).

Os animais 4 e 6 apresentaram mais áreas de astrocitose e astrogliose que os demais animais deste estudo e também foram os únicos com imunomarcação pelo $\beta$ APP. Isto se deve possivelmente pelo tempo de sobrevivência dos animais, no qual no caso do animal 6 , sabe-se que o tempo de sobrevivência foi de quase 48 horas. No animal 4 não há esta informação, porém sabe-se que o animal sobreviveu por algumas horas após o início dos sintomas, havendo, portanto, tempo para resposta do SNC à injuria.

Os animais 1 e 7 apresentaram marcação negativa para o $\beta A P P$ e nenhuma imunomarcação diferente da normal pelos anticorpos GFAP e vimentina. Considerando a extensão e gravidade da lesão observada no animal 1, é provável que sua morte tenha ocorrido imediatamente após o trauma, não havendo, portanto, tempo de resposta do SNC à injuria. No caso 7 o felino foi encontrado morto em um box junto com um cão, porém o exame necroscópico não revelou mais lesões, sinais de trauma, outras alterações em demais órgãos ou sinais de ataque do cão. Apesar dos sinais de autólise observados durante análise das lâminas coradas por HE, houve marcação normal do tecido nervoso pelo GFAP e vimentina, o que torna possível descartar, neste caso, a não imunomarcação pela autólise, observada em alguns estudos (THÜR et al. 1997, ARSLAN et al. 2004). Portanto, é possível que o animal tenha morrido imediata ou rapidamente após a injúria, visto que as lesões observadas também foram extensas e severas.

Estes resultados mostram que na maior parte dos casos não houve informações concretas sobre o que levou o animal ao óbito, revelando a importância de um exame necroscópico minucioso, detalhado e, se possível, documentado, registrando fotograficamente todo o exame, pois pela presença de lesões condizentes com traumas pode haver a suspeita de maus-tratos 
(SALVAGNI et al., 2012; GERDIN; MCDONOUGH, 2013; CUEVAS et al., 2016). No caso de suspeita ou certeza de maus-tratos, salienta-se a importância da realização de exame radiográfico antes do exame necroscópico, para determinar exatamente a localização das lesões, no caso de fraturas principalmente, ou de projéteis de armas de fogo (MUNRO; MUNRO, 2008; MERCK et al., 2013).

\subsection{CONCLUSÃO}

Conclui-se no presente estudo que cães e gatos com TCE apresentaram lesões histologicamente caracterizadas por hemorragias multifocais em meninge e neuroparênquima em diversas regiões, além de edema, necrose e congestão, principalmente. A lesão axonal caracterizou-se pela formação de esferoides axonais, bulbos axonais e longos axônios varicosos. Esta característica foi observada em apenas 2 animais deste estudo, e destes apenas um animal (caso 6) apresentou um padrão de lesão axonal traumática difusa, confirmada pela presença de acentuada marcação pelo anticorpo ßAPP. Adicionalmente, foi observada astrocitose e astrogliose em cinco animais, principalmente das áreas próximas às lesões, avaliadas pelos anticorpos GFAP e vimentina. 


\section{REFERÊNCIAS}

ADAMS, J. H., DOYLE, D., GRAHAM, D. I., LAWRENCE, A. E., MCLELLAN, D. R. Diffuse axonal injury in head injuries caused by a fall. Lancet, v. 2, n. 84178418, p.1420-2, 1984.

ADAMS, J. H., DOYLE, D., FORD, I., GENNARELLI, T. A., GRAHAM, D. I., MCLELLAN, D. R. Diffuse axonal injury in head injury: definition, diagnosis and grading. Histopathology, v. 15, n. 1, p. 49-59, 1989.

ADAMS, J. H., GRAHAM, D. I., GENNARELLI, T. A., MAXWELL, W. L. Diffuse axonal injury in non-missile head injury. J Neurol Neurosurg Psychiatry v. 54, n. 6 , p. 481-483, 1991

ALDRICH, E. F., LEVIN, H. S., EISENBERG, H. M. Mild head injury in children. In: Youmans J.R, editor. Neurological surgery. 4aㅡ ed. Philadelphia: WB Saunders; 1996. p.1719-29.

ANDERSON, R., MCLEAN, J. Biomechanics of closed head injury. In: REILLY, P. L., BULLOCK, R. (eds) Head injury. Pathophysiology and management. Hodder Arnold, London, p. 26-40, 2005

ARSLAN, A., SAGLAM, Y. S., TEMUR, A. Detection of rabies viral antigens in non-autolysed and autolysed tissues by using an immuno-peroxidase technique. Vet. Rec, v. 155, n. 18, p. 550-552, 2004.

BLUMBERGS, P. C., SCOTT, G., MANAVIS, J., WAINWRIGHT, H., SIMPSON, D. A., MCLEAN, A. J. Staining of amyloid precursor protein to study axonal damage in mild head injury. Lancert, v.344, n.8929, p. 1055-1056, 1994.

BLUMBERGS, P. C., JONES, N. R., NORTH, J. B. Diffuse axonal injury in head trauma. J Neurol Neurosurg Psychiatry, v. 52, n. 7, p. 838-41, 1989

BLUMBERGS, P., REILLY, P., VINK, R. Trauma. In: LOUIS DN, LOVE S, ELLISON DW, eds Greenfield's Neuropathology, vol. 1. Hodder Arnold, London, UK, 2008, pp. 733-812. 
BOR-SENG-SHU E. AGUIAR P.H., ALMEIDA LEME R.J., MANDEL M., ANDRADE A.F., MARINO J.R., R. Epidural hematomas of the posterior cranial fossa. Neurosurg Focus, v. 16, n. 2, ECPI, 2004.

BOR-SENG-SHU, E., HIRSCH, R., TEIXEIRA, M. J., ANDRADE, A. F., MARINO R. JR. Cerabral hemodynamic changes gauged by transcranial Doppler ultrasonography in patientes with postraumatic brain swelling treates bu surgical decompression. J Neurosurg, v. 104, n. 1, p. 93-100, 2006.

CHESNUT, R. M. The management of severe traumatic brain injury. Emerg Med Clin North Am, v. 15, n. 3, p. 581-604, 1997.

CHRISTMAN, C. W., GRADY, M. S., WALKER, S. A., HOLLOWAY, K. L., POVLISHOCK, J. T. Ultrastructural studies of diffuse axonal injury in humans. $J$ Neurotrauma, v. 11, n. 2, p. 173-186, 1994

CLARK, R. S. B., KOCHANEK, P. Brain Injury. Boston, MA: Kluwer Academic; 2001, p. 367.

CUEVAS, S. E. C., SIQUEIRA, A., SALVANGI, F. A., MAIORKA, P. C. Lesões não acidentais em gatos domésticos: estudo de 90 necropsias relativas a traumas produzidos por energia de ordem mecânica. Clínica Veterinária, ano XXI, n.120, p.80-87, 2017

DEWEY, C. W., DOWNS, M. O., ARON, D. N., MAHAFFEY, E. A. Acute traumatic intracranial haemorrhage in dogs and cats. Vet Comp Orthop Traumatol, v. 6, n. 3, p.153-158, 1993.

DEWEY, C. W. Emergency management of the head trauma patient. Vet Clin North Am Small Anim Pract, v. 30, n. 1, p. 207-225, 2000.

DOLINAK, D., REICHARD, R. R. An overview of inflicted head injury in infants and young children, with a review of beta-amyloid precursor protein immunohistochemistry. Archives of Pathology and Laboratory Medicine, v. 130, n. 5 , p. $712-7,2006$ 
DONG Y, BENVENISTE EN. Immune function of astrocytes. Glia, v. 36, n. 2, p. 180-190, 2001

ENG LF., GHIRNIKAR RS. GFAP and astrogliosis. Brain Pathol, v. 4, n.3, p. 229-237, 1994.

FINNIE, J. W. Forensic Pathology of Traumatic Brain Injury. Veterinary Pathology, v. 53, n. 5, p. 962-978, 2016

FINNIE, J. W. Pathology of traumatic brain injury. Vet Res Commun, v. 38, n. 4, p. 297-305, 2014

FLETCHER, E. J., SYRING, R. S. Traumatic brain injury, In: SILVERSTEIN DC, HOPPER K. eds. Small Animal Critical Care Medicine, 1st ed. Philadelphia:

Elsevier Saunders; 2009, pp. 658-662

FRANCEL, P., ALVES W. N., JANE, JÁ. Mild head injury in neurological surgery. In: Youmans J.E. editor. Neurological surgery. 4를 ${ }^{a}$. Philadelphia: WB Saunders: 1996. p.1595-617.

GEBHARD, F., LANG, M. H. Polytrauma - pathophysiology and management principles. LANGenbecks Arch Chir, v. 393, n. 6, p. 825-31, 2008.

GEDDES, J. F., WHITWELL, H. L., GRAHAM, D. I. Traumatic axonal injury: practical issues for diagnosis in medicolegal cases. Neuropathology and Applied Neurobiology, v. 26, n. 2, p. 105-16, 2000

GENNARELLI, T. A., THIBAULT, L. E., ADAMS, J. H., GRAHAM, D. I., THOMPSON, C. J., MARCINCIN, R. P. Diffuse axonal injury and traumatic coma in the primate. Ann Neurol, v. 12, n. 6. p. 564-74, 1982

GENNARELLI T.A., GRAHAM D.I. Neuropathology of the head injuries. Semin Clin Neuropsychiatry, v. 3, n.3, p. 160-75, 1998. 
GENTLEMAN SM, NASH MJ, SWEETING CJ., GRAHAM, D. I., ROBERTS, G. W. Related beta-amyloid precursor protein (beta APP) as a marker for axonal injury after head injury. Neurosci Lett, v. 160, n. 2, p. 139-44, 1993

GERDIN, J. A.; MCDONOUGH, S. P. Forensic Pathology of Companion Animal Abuse and Neglect. Veterinary Pathology, v.50, n.6, p.994-1006, 2013.

GOODMAN, J. C. Pathophysiology - mild and moderate brain injuries. In: MARION DW, editor. Traumatic brain injury. New York: Thieme, 1999; p.14354.

HOPKINS, A. L. Head trauma. Vet Clin North Am Small Anim Pract 1996; v. 26, n.4, p. $875-891,1996$

IWATA A, CHEN XH, MCINTOSH TK., BROWNE, K. D., SMITH, D. H., Longterm accumulation of amyloid- $\beta$ in axons following brain trauma without persistent upregulation of amyloid precursor protein genes. J Neuropathol Exp Neurol, v. 61, n. 12, p. 1056-1068, 2002

LEWEN A, LI GL, NILSSON P., OLSSON, Y., HILLERED, L. Traumatic brain injury in rat produces changes of $\beta$-amyloid precursor protein immunoreactivity. Neuroreport, v.6, n. 12, p. 357-360, 1995

LORENZ, M. D., COATES, J. R., KENT, M. Stupor or coma. In: Handbook of veterinary neurology. $5^{\mathrm{a}}$ ed. United States of America: Elsevier; 2011. p.346-83.

MAXWELL WL, WATTS C, GAHAM DI, GENNARELLI TA. Ultrastructural evidence of axonal shearing as a result of lateral acceleration of the head in non-human primates. Acta Neuropathol, v. 86, n. 2, p.136-144, 1993.

MERCK, M. D.; MILLER, D. M.; MAIORKA, P. C. CSI: the animal as evidence. In: MERCK, M. D. Veterinary forensics: animal cruelty investigations. 2ed. lowa: Wiley-Blackwell, 2013. p. 37-68

MCCRORY, P. R., BERKOVIC, S. F. Concussion: the history of clinical and pathophysiological concepts and misconceptions. Neurology, v. 57, n. 12, p. 2283-9, 2001 
MCCRORY, P. When to retire after concussion? Br J Sports Med, v. 35, n. 6, p. 380-2, 2001

MONTGOMERY DL. Astrocytes: form, functions, and roles in disease. Vet Pathol, v. 31, n. 2, p. 145-167, 1994.

MUNRO, R.; MUNRO, H.M.C. Wounds and injuries. In: . Animal abuse and unlawful killing: forensic veterinary pathology. Edinburgh, UK: Saunders Elsevier, p.30-47, 2008

PARIKH, S., KOCH, M., NARAYAN, R. K. Traumatic brain injury. International Anesthesiology Clinics, v. 45, n. 3, p. 119-35, 2007

PEKNY M, JOHANSSON CB, ELIASSON C, STAKEBERG J, WALLÉN A, PERLMANN T, LENDAHL U, BETSHOLTZ C, BERTHOLD CH, FRISÉN J. Abnormal reaction to central nervous system injury in mice lacking glial fibrillary acidic protein and vimentin. J Cell Biol, v. 145, n. 3, p. 503-514, 1999

PETITO CK, MORGELLO S, FELIX JC, LESSE ML. The two patterns of reactive astrocytosis in postischemic rat brain. $\mathrm{J}$ Cer Blood Flow Metab, v.10, $\mathrm{n}$. 6, p. $850-859,1990$

PIERCE JE, TROJANOWSKI JQ, GRAHAM DI, SMITH, D. H., MCINTOSH, T. $\mathrm{K}$. Immunohistochemical characterization of alterations in the distribution of amyloid percursor proteins and $\beta$-amyloid peptide after experimental brain injury in the rat. J Neurosci, v. 16, n.3, p. 1083-1090, 1996

PROULX J, DHUPA N. Severe brain injury: part I. Pathophysiology. Compend Contin Educ Pract Vet, v. 20, p. 897-905, 1998

MESQUITA, L. P., HORA, A. S., SIQUEIRA, A., SALVAGNI, F. A., BRANDÃO, P. E., MAIORKA, P. C. Glial response in the central nervous system of cats with feline infectious peritonitis. Journal of Feline Medicine and Surgery, v. 18, n. 12, p. $1023-1030,2016$ 
OEHMICHEN M, EISENMENGER W, RAFF G, RAFF G, BERGHAUS G. Brain macrophages in human cortical contusions as an indicator of survival period. Forensic Sci Int, v. 30, n. 4, p.281-301, 1986

OEHMICHEN, M., MEISSNER, C., SCHMIDT, V., PEDAL, I., KONIG, H. G., SATERNUS, K. S. Axonal Injury - a diagnostic tool in forensic neuropathology? A review. Forensic Science International, v. 95, n. 1, p. 67-83, 1998

OEMICHEN M, MEISSNER C, VON WURMB-SCHWARK N, SCHWARK, T. Methodical approach to brain ischemia-hypoxia as a fundamental problem in forensic neuropathology. Legal Med, v. 5, n. 4, p. 190-201, 2003

OMMAYA, A.K., GOLDSMITH, W., THIBAULT, L. Biomechanics and neuropathology of adult and paediatric head injury. British Journal of Neurosurgery, v. 16, n. 3, p. 220-242, 2002

POVLISHOCK, J. T., CHRISTMAN, C. W. The pathobiology of traumatically induced axonal injury in animals and humans - A review of current thoughts. Journal of Neurotrauma, v. 12, n. 4, p. 555-564, 1995

REICHARD, R. R., WHITE, C. L., HLADIK, C. L., DOLINAK, D. Beta-Amyloid Precursor Protein Staining in Nonhomicidal Pediatric Medicolegal Autopsies. Journal of Neuropathology and Experimental Neurology, v.62, n.3, p.237247, 2003

REICHARD, R. R., SMITH, C., GRAHAM, D. I. The significance of beta-APP immunoreactivity in forensic practice. Neuropathology and Applied Neurobiology, v. 31, n. 3, p. 304-13, 2005

ROE, W. D., MAYHEW, I. G., JOLLY, R. D., MARSHALL, J., CHILVERS, B. L. Traumatic brain injury, axonal injury and shaking in New Zealand sea lion pups. The Veterinary Journal, v. 200, n.1, p. 96-102, 2014

SALVAGNI, F. A.; DE SIQUEIRA, A.; MARIA, A. C. B. E.; DOS SANTOS, C. R.; RAMOS, A. T.; MAIORKA, P. C. Forensic veterinary pathology: old dog learns a trick. Brazilian Journal of Veterinary Pathology, v.5, n. 2, p. 37-39, 2012. 
SANJITH S. Traumatic axonal injury in mild to moderate head injury - an illustrated review. Indian Journal of Neurotrauma (IJNT), v. 8, n. 2, p. 71-76, 2011

SANDE, A. Traumatic brain injury: a review of pathophysiology and management. J Vet Emerg Crit Care, v. 20, n. 2, p. 177-90, 2012

SAWAUCHI S., MURAKAMI S., OGAWA T., ABE T. Mechanism of injury in acute subdural hematoma and difuse brain injury: analysis of 587 cases in the Japan. Neurotrauma Data Bank. No Shinkei Geka, v. 35, n. 7, p. 665-71, 2007

SEIM, III H.B.S. Cirurgia do encéfalo. In: Fossum TW. Cirurgia de pequenos animais. $3^{\text {a }}$ ed. São Paulo: Elsevier; 2007. p.1379-97.

SHERRIFF, F. E., BRIDGES, L. R., SIVALOGANATHAN, S. Early detection of axonal injury after human head trauma using immunocytochemistry for betaamyloid precursor protein. Acta Neuropathol, v. 87, n. 1, p. 55-62, 1994

SMITH, D. H, CHEN, X. H., NONAKA, M., TROJANOWSKI, J. Q., LEE, V. M., SAATMAN, K. E., LEONI, M. J., XU, B. N., WOLF, J. A., MEANEY, D. F. Accumulation of amyloid beta and tau and the formation of neurofilament inclusions following diffuse brain injury in the pig. J Neuropathol Exp Neurol, v. 58, n. 9, p. 982-992, 1999

SMITH, D. H., MEANEY, D. F. Axonal damage in traumatic brain injury. Neuroscientist v. 6, n. 6, p. 483-495, 2000

SMITH, D. H., CHEN, X. H., IWATA, A., GRAHAM, D. I. Amyloid $\beta$ accumulation in axons after traumatic brain injury in humans. J Neurosurg, v. 98 , n. 5, p. 1072-1077, 2003

SPRAKER, T. R., LANDER, M. E. Causes mortality in Northern fur seals (Callorhinus ursinus), St. Paul Island, Pribilof Islands, Alaska, 1986-2006. Journal of Wildlife Diseases, v. 46, n. 2, p. 450-473, 2010

STONE, J. R., OKONKWO, D. O., SINGLETON, R. H., MUTLU, L. K., HELM, G. A., POVLISHOCK, J. T. Caspase-3-mediated cleavage of amyloid precursor 
protein and formation of amyloid Beta peptide in traumatic axonal injury. $J$ Neurotrauma, v. 19, n. 5, p. 601-614, 2002

TAKAMIYA Y, KOHSAKA S, TOYA S, OTANI M, TSUKUDA Y. Immunohistochemical studies on the proliferation of reactive astrocytes and the expression of cytoskeletal proteins following brain injury. Dev Brain Res, v. 466, n. 2. p. 201-210, 1988

TEASDALE G., MATHEW P. Mechanisms of cerebral concussion, contusion and others effects of head injury. In: Youmans JR. editor. 4 ed., Philadelphia, WB Saunders; 1996. p.1533-48

THÜR B., HILBE M., STRASSER M., EHRENSPERGER F. Immunohistochemical diagnosis of pestivirus infection associated with bovine and ovine abortion and perinatal death. Am. J. Vet. Res, v. 58, n. 12, p.1371-1375, 1997.

VERNEAU, K. Management of head trauma. In: Proceedings of Veterinary Neurology Annual Symposium; 2005, Davis. Davis: VNAS; 2005.

WILKINSON, A. E., BRIDGES, L. R., SIVALOGANATHAN, S. Correlation of survivaltime with size of axonal swellings in diffuse axonal injury. Acta Neuropathol, v. 98, n. 2, p. 197-202, 1999. 
Lesão Axonal Difusa e Reação Astrocitária em Gato com Traumatismo Cranioencefálico 


\section{Lesão axonal difusa e reação astrocitária em gato com traumatismo cranioencefálico}

No presente capítulo é apresentado um artigo que será submetido ao periódico Veterinary Pathology como brief communication.

\subsection{Resumo}

A lesão axonal é uma das características mais importantes e comuns do traumatismo cranioencefálico (TCE) difuso e ocorre devido o rompimento físico dos axônios. O presente estudo busca avaliar a lesão axonal em um felino arremessado ao chão que apresentou midríase, apatia, paresia e inchaço da região frontal da cabeça. Foi realizada necropsia na qual observou-se extensa hemorragia cobrindo toda a calota e musculatura da cabeça, coágulos e fratura em região orbital de osso temporal em lateral esquerda. As lesões microscópicas se caracterizaram por extensos focos hemorrágicos em meninge e neuroparênquima de lobo temporal e lobo piriforme principalmente, além de necrose e edema acentuado. A imunohistoquímica pelo $\beta A P P$ revelou marcação em diferentes regiões de axônios inchados caracterizados por esferoides, bulbos axonais e axônios varicosos, enquanto a marcação por GFAP e vimentina revelou evidente astrocitose e astrogliose. As lesões encontradas e a imunohistoquímica pelo $\beta A P P$ demonstram a ocorrência da lesão axonal difusa em decorrência do TCE.

Palavras-chave: $\beta$-amiloide, traumatismo cranioencefálico, lesão axonal, gato.

\subsection{Abstract}

Axonal injury is one of the most important and common features of traumatic brain injury (TBI) and occurs due to physical disruption of axons. The present study aims to evaluate the axonal injury in a feline thrown to the ground that presented mydriasis, apathy, paresis and swelling of the frontal region of the 
head. Necropsy revealed extensive hemorrhage all over the skull and musculature of the head, clots and fracture in the orbital region of temporal bone in the left lateral. Microscopic lesions were characterized by extensive subdural hemorrhage and in the neuroparenchyma of temporal lobe and piriform lobe, in addition to necrosis and marked edema. Immunohistochemistry by $\beta$ APP labeled axonal swellings, bulbs and varicosities, whereas GFAP and vimentin labeling revealed astrocytosis and astrogliosis. The lesions and the immunohistochemistry by $\beta$ APP demonstrate the occurrence of diffuse axonal lesion as a result of TBI.

Keywords: $\beta$-amyloid, traumatic brain injury, axonal injury, cat

O traumatismo cranioencefálico (TCE) caracteriza-se por um dano físico ao tecido cerebral, acometendo as funções cerebrais normais de forma temporária ou permanente (PARIKH et al., 2007). A lesão axonal é uma das características mais importantes e comuns do TCE difuso em humanos (SMITH; MEANEY, 2000) e caracteriza-se pela injúria generalizada aos axônios da substância branca, ocorrendo em diversos graus de lesão, desde uma concussão discreta a lesões fatais severas (BLUMBERGS et al., 1994; OEHMICHEN et al., 1998). Ela ocorre principalmente por forças de aceleração/desaceleração que resultam mais frequentemente em dano difuso (OMMAYA et al., 2002). A proteína precursora do $\beta$-amiloide ( $\beta A P P)$ é um polipeptídeo sintetizado pelos neurônios e transportado por transporte axonal rápido. $\mathrm{A}$ imunohistoquimica com o $\beta$ APP pode ser usada para determinar a distribuição e gravidade da lesão axonal, visto que essa lesão interrompe o transporte axonal, causa acúmulo de $\beta A P P$ em axônios inchados ou bulbos axonais (BLUMBERGS et al., 2008).

Um gato, fêmea, SRD, 2 meses de idade foi encaminhado ao Serviço de Patologia Animal da Faculdade de Medicina Veterinária e Zootecnia - USP para realização de necropsia documentada. $O$ animal foi arremessado ao chão por um dos proprietários, tendo sido levada a hospital veterinário no dia seguinte do ocorrido apresentando midríase, paresia e inchaço em região 
frontal do crânio, onde realizou-se tratamento emergencial, porém o animal veio a óbito nesse mesmo dia.

Foi realizada necropsia documentada completa com coleta de material para exame histopatológico e imunohistoquimica para os anticorpos proteína precursora do $\beta$-amiloide ( $\beta A P P$ ), da proteína glial fibrilar ácida (GFAP) e vimentina, para detecção de lesão axonal difusa e reação astrocitária. $O$ protocolo da reação imunohistoquímica compreendia recuperação antigênica em tampão citrato $\mathrm{pH} 6,0$, incubação dos anticorpos primários $\beta A P P$, GFAP e vimentina overnight em geladeira, nas diluições de 1:200, 1:8000 e 1:4000, respectivamente. A revelação foi realizada utilizando-se o substrato DAB (3,3'diaminobenzidina) e contra coloração com hematoxilina.

$\mathrm{Na}$ necropsia observou-se aumento de volume em região frontal do crânio, hiperemia e edema em mucosa palpebral bilateral. Ao remover a pele do crânio observou-se extensa hemorragia cobrindo toda a calota e musculatura da cabeça, com grande quantidade de coágulos, intensa hiperemia em crânio, além de área focal de hemorragia em região de articulação atlanto-occiptal e fratura em região orbital de osso temporal em lateral esquerda. A abertura do crânio havia intensa hemorragia subdural em região de lobo temporal direito e foco hemorrágico subdural em medula em região da articulação atlanto-occipital. O cérebro e cerebelo encontram-se edemaciados, hiperêmicos, com áreas multifocais de hemorragia, nota-se ainda, área em região dorsal de lobo frontal de moderada destruição de massa encefálica. A porção ventral do encéfalo apresenta-se hiperêmico com áreas multifocais hemorrágicas (lesões de contragolpe). Também se observou hemorragia em nervos oculares. Não apresentava alterações nos demais órgãos.

Microscopicamente, o espaço subdural encontra-se amplamente distendido por grande quantidade de células vermelhas (hemorragia). A área de golpe caracteriza-se por extenso foco hemorrágico em lobo piriforme adjacente à cápsula interna e espaços perivascular e perineural severamente distendidos (edema), bem como grande quantidade de neurônios com citoplasma eosinofílico, diminuídos de volume, e núcleo cariolítico, caraterizando necrose neuronal. $\mathrm{O}$ neuroparênquima apresenta área localmente extensa com vacúolos (espongiose), áreas de necrose liquefativa e 
esferoides axonais multifocais. Vasos sanguíneos com pequeno número de macrófagos, linfócitos e raros neutrófilos. A área de contragolpe localizada em lobo piriforme contralateral, apresenta focos hemorrágicos com necrose central, necrose neuronal, esferoides axonais, reação vascular e acentuada vacuolização do neuroparênquima em tecido adjacente ás áreas de lesão. Também se observaram extensas hemorragias em ventrículo lateral envolvendo o hipocampo e neuroparênquima adjacente, além de discreta hemorragia em plexo coroide. Também foi observado acentuado edema e presença de esferoides axonais em tronco encefálico.

A lesão axonal foi evidenciada pela reação imunohistoquimica com 0 ßAPP, no qual observou-se acentuada marcação multifocal de axônios em cápsula interna, adjacente à extensa área de hemorragia em lobo piriforme, e em tronco encefálico, bem como moderada marcação em substância branca de lobo temporal e discreta em corpo caloso. As marcações mais acentuadas ocorreram em áreas adjacentes à extensas áreas de hemorragia em meninge e neuroparênquima. A imunomarcação se deu de três aspectos: axônios inchados e redondos de tamanhos variados chamados de esferoides axonais; axônios inchados e ovalados, denominados de bulbos axonais ou, se seccionados longitudinalmente, apresentam inchaço irregular ao longo do axônio, recebendo o nome de axônios varicosos. Os resultados obtidos pela marcação do $\beta$ APP neste caso são semelhantes aos encontrados nos estudos de lesão axonal em casos de TCE em focas (SPRAKER; LANDER, 2010) e em filhotes de leões marinhos (ROE et al., 2014).

A reação astrocitária foi avaliada através da imunomarcação dos anticorpos GFAP e vimentina e foi possível observar que os astrócitos reativos apresentaram citoplasma abundante mais fortemente corado pelo anti-GFAP, prolongamentos em maior quantidade, mais longos e com diâmetro maior (astrogliose) que astrócitos de outras áreas do encéfalo ou pertencentes ao grupo controle. Os núcleos também se apresentaram maiores e com nucléolos evidenciados. A imunomarcação pela vimentina em astrócitos é semelhante à do GFAP, marcando intensamente seu citoplasma e prolongamentos quando há expressão dessa proteína em resposta à injúria. Observou-se acentuada marcação pela vimentina em astrócitos da cápsula interna e lobo piriforme, moderada marcação em córtex de lobo temporal e discreta marcação em 
hipocampo. O GFAP marcou acentuadamente 0 lobo piriforme, moderadamente o córtex temporal e de forma discreta o tronco encefálico. Através da marcação da vimentina também foi possível observar acentuada neovascularização do neuroparênquima. A imunomarcação tanto pelo GFAP quanto pela vimentina se deu principalmente nas áreas próximas às lesões observadas no HE.

A imunohistoquimica do anticorpo $\beta A P P$ demonstrou que $o$ felino apresentou lesões axonais condizentes com lesão axonal difusa, caracterizada pela presença de histórico de trauma com imunomarcação dispersa ou em grupos de axônios inchados ou formando bulbos axonais pelo $\beta A P P$ em corpo caloso, substância branca hemisférica, e tronco encefálico, em um padrão não consistente com lesão axonal vascular (REICHARD et al, 2003). As reações dos anticorpos vimentina e GFAP demonstraram áreas de astrocitose e astrogliose principalmente nas áreas próximas às lesões, nas áreas do córtex de lobo temporal e lobo piriforme, evidenciados tanto pelo GFAP quanto pela vimentina. Este fato endossa a resposta do tecido à injuria, visto que os astrócitos são células que respondem prontamente a ampla variedade de insultos ao tecido nervoso (DONG; BENVENISTE, 2001) tais como isquemia, trauma, desmielinização, inflamação, neurodegeneração e infecções virais (ENG; GHIRNIKAR, 1994).

A imunohistoquímica pelo $\beta$ APP demonstrou que houve lesão axonal difusa em decorrência do TCE sofrido pelo animal, provavelmente pelas forças de aceleração/desaceleração sofridas quando o animal foi arremessado. 
Figura 14 - Traumatismo cranioencefálico de felino, fêmea, SRD, 2 meses.

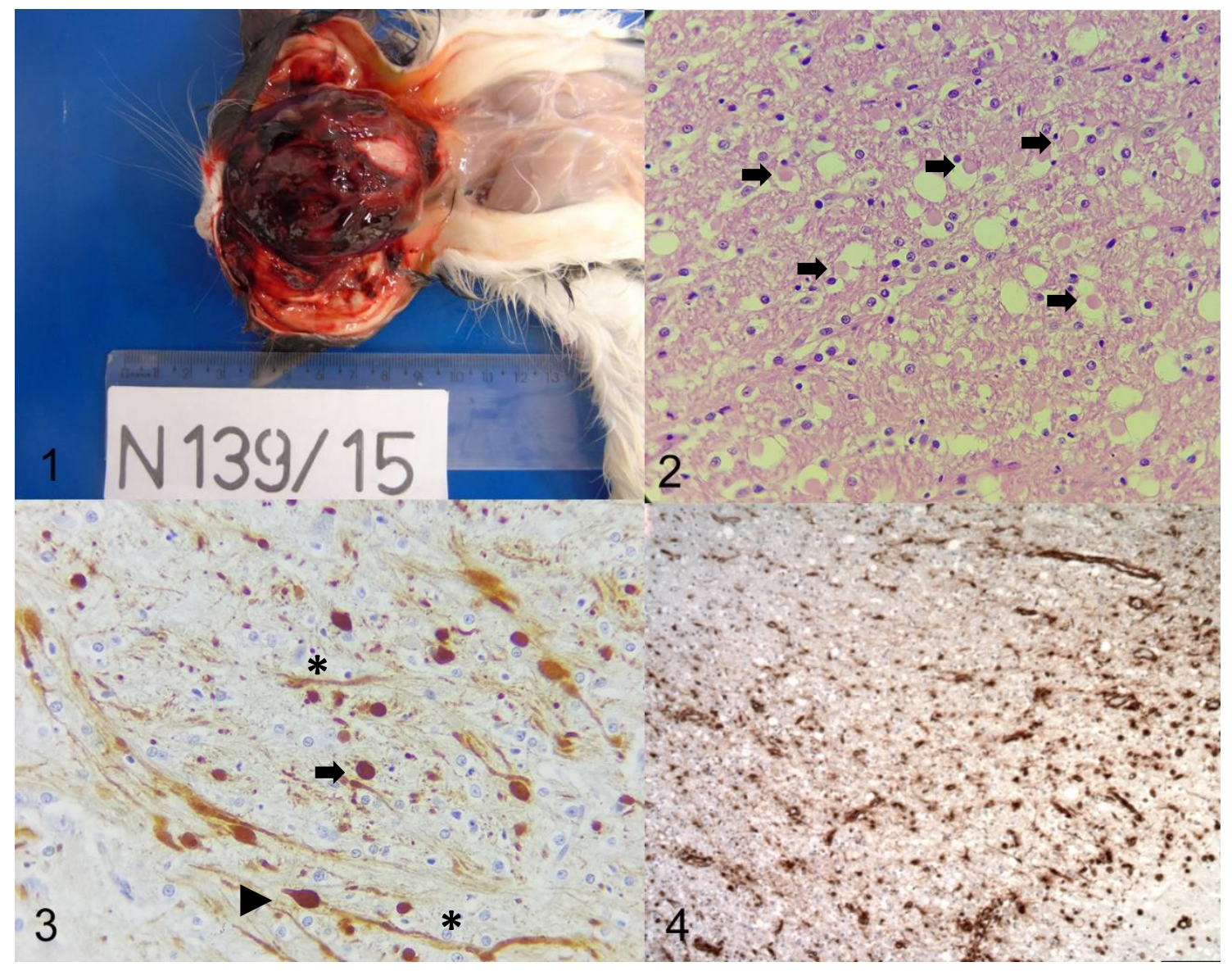

Legenda: Figura 1. Cabeça, felino. Extensa hemorragia e presença de coágulos em toda região de crânio. Figura 2. Neuroparênquima de lobo piriforme com inúmeros esferoides axonais (setas) e acentuado edema. Hematoxilina e eosina (HE). Figura 3. Neuroparênquima, cápsula interna. Marcação de axonios pelo ßAPP. Presença de esferoides axonais (setas), bulbos axonais (cabeça de setas) e axônios varicosos (asterisco). Figura 4. Neuroparênquima, cápsula interna. Marcação por vimentina de astrócitos e novos vasos (neovascularização) 


\section{REFERÊNCIAS}

BLUMBERGS, P. C., SCOTT, G., MANAVIS, J., WAINWRIGHT, H., SIMPSON, D. A., MCLEAN, A. J. Staining of amyloid precursor protein to study axonal damage in mild head injury. Lancert, v.344, n.8929, p. 1055-1056, 1994.

BLUMBERGS, P., REILLY, P., VINK, R. Trauma. In: LOUIS DN, LOVE S, ELLISON DW, eds Greenfield's Neuropathology, vol. 1. Hodder Arnold, London, UK, 2008, p. 733-812.

DONG Y, BENVENISTE EN. Immune function of astrocytes. Glia, v. 36, n. 2, p. 180-190, 2001

ENG LF., GHIRNIKAR RS. GFAP and astrogliosis. Brain Pathol, v. 4, n.3, p. 229-237, 1994.

OEHMICHEN, M., MEISSNER, C., SCHMIDT, V., PEDAL, I., KONIG, H. G., SATERNUS, K. S. Axonal Injury - a diagnostic tool in forensic neuropathology? A review. Forensic Science International, v. 95, n. 1, p. 67-83, 1998

OMMAYA, A.K., GOLDSMITH, W., THIBAULT, L. Biomechanics and neuropathology of adult and paediatric head injury. British Journal of Neurosurgery, v. 16, n. 3, p. 220-242, 2002

PARIKH, S., KOCH, M., NARAYAN, R. K. Traumatic brain injury. International Anesthesiology Clinics, v. 45, n. 3, p. 119-35, 2007

REICHARD, R. R., WHITE, C. L., HLADIK, C. L., DOLINAK, D. Beta-Amyloid Precursor Protein Staining in Nonhomicidal Pediatric Medicolegal Autopsies. Journal of Neuropathology and Experimental Neurology, v.62, n.3, p.237-247, 2003

ROE, W. D., MAYHEW, I. G., JOLLY, R. D., MARSHALL, J., CHILVERS, B. L. Traumatic brain injury, axonal injury and shaking in New Zealand sea lion pups. The Veterinary Journal, v.200, n. 1, p. 96-102, 2014 
SMITH, D. H., MEANEY, D. F. Axonal damage in traumatic brain injury. Neuroscientist v. 6, n. 6, p. 483-495, 2000

SPRAKER, T. R., LANDER, M. E. Causes mortality in Northern fur seals (Callorhinus ursinus), St. Paul Island, Pribilof Islands, Alaska, 1986-2006. Journal of Wildlife Diseases, v. 46, n. 2, p. 450-473, 2010 